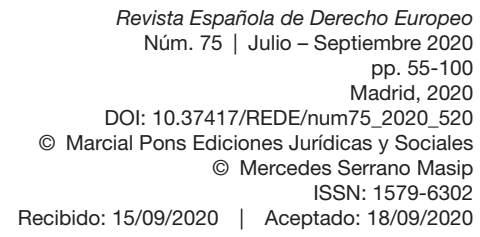

\title{
INCORPORACIÓN DEL ENJUICIAMIENTO EN AUSENCIA DE MENORES AL SISTEMA PROCESAL PENAL ESPAÑOL CON APOYO EN LA JURISPRUDENCIA DEL TEDH Y LA NORMATIVA DE LA UNIÓN EUROPEA
}

\author{
INCORPORATION OF IN ABSENTIA JUVENILE TRIALS INTO THE \\ SPANISH CRIMINAL SYSTEM BASED ON THE ECTHR CASE-LAW \\ AND EU LEGISLATION
}

Mercedes Serrano Masip*

RESUMEN: El enjuiciamiento en ausencia de menores acusados es una de las principales cuestiones controvertidas en el sistema de justicia penal español. Desde la entrada en vigor de la ley que regula en la actualidad el proceso penal de menores, la LO 5/2000, los tribunales que han de interpretarla y aplicarla han mantenido y continúan defendiendo posturas radicalmente opuestas acerca de si el juicio puede celebrarse sin estar presente el menor en la sala de vistas. Los efectos negativos de esta divergencia, en especial la inseguridad jurídica que genera, solo pueden ser superados a través de una reforma legal. En este trabajo se analizan las bases esenciales en las que ha de inspirarse dicha reforma. Estas son la jurisprudencia del TEDH sobre el derecho del acusado a estar presente en el proceso penal y los instrumentos normativos UE que han abordado, desde las perspectivas del reconocimiento mutuo y de la aproximación legislativa, el tema del enjuiciamiento y la condena en ausencia del acusado. Con respecto a la jurisprudencia del

* Mercedes Serrano Masip es profesora titular de Derecho Procesal en la Universidad de Lleida. Correo-e: merche.serrano@udl.cat. ORCID ID: 0000-0002-6529-3428.

El presente trabajo se ha realizado en el marco del proyecto financiado por el Ministerio de Ciencia, Innovación y Universidades [PGC2018-094209-b-100] titulado La evolución del espacio judicial europeo en materia civil y penal. Su influencia en el proceso español. 
TEDH, son examinadas, en particular, las garantías procesales exigidas para que la renuncia a aquel derecho sea compatible con un juicio justo. Y en lo atinente a la normativa UE, además de comprobar cómo se lleva a cabo la recepción de la jurisprudencia del TEDH, se proponen los criterios que deberían acotar la eficacia de la cláusula de"no regresión", incluida en la Dir. 2016/800, a los efectos de no impedir una futura modificación de la LO 5/2000.

PALABRAS CLAVE: proceso penal de menores; derecho a estar presente en el juicio; discrepancia judicial; cláusula de no regresión.

ABSTRACT: Juvenile trial in absentia is one of the main controversial issues in the Spanish criminal justice system. Ever since the law that currently regulates the juvenile criminal process - LO 5/2000- entered into force, there has been a significant inter-jurisdictional disparity in whether the trial may be held without the minor being present in the courtroom. The negative effects of this divergence, especially the legal uncertainty, could be overcome through a legislative reform. Consequently, the paper deals with the foundations that should inspire the before mentioned reform. These foundations are the ECtHR case-law on the right of the accused to be present at trial, and the EU legislation that has tackled, from the perspectives of mutual recognition and legislative approximation, the topic of in absentia judgment and conviction. As regards the ECtHR case-law, procedural safeguards related to the waiver of the right to be present at trial are examined to determine its compatibility with due process. Concerning EU legislation, in addition to checking how the reception of the ECtHR case-law has been accomplished, some criteria are proposed that should limit the effectiveness of "nonregression" clause, included in the Dir. 2016/800, for the purpose to not prevent a future reform of the LO 5/2000.

KEYWORDS: juvenile criminal trial; right to be present at trial; inter-jurisdictional disparity; non-regression clause.

SUMARIO: INTRODUCCIÓN.-1. ENJUICIAMIENTO EN AUSENCIA EN LA JURISPRUDENCIA DEL TRIBUNAL EUROPEO DE DERECHOS HUMANOS: 1.1. Compatibilidad con el derecho a un proceso equitativo de la renuncia a comparecer en el propio juicio. 1.2. Particularidades del enjuiciamiento en ausencia en segunda instancia.-2. ENJUICIAMIENTO EN AUSENCIA EN INSTRUMENTOS NORMATIVOS DE LA UNIÓN EUROPEA Y SU INTERPRETACIÓN POR EL TJUE: 2.1. Recepción de la jurisprudencia del TEDH en las Decisiones marco 2002/584/JAI y 2009/299/JAI. 2.2. Continuidad en la regulación del enjuiciamiento en ausencia en las Directivas (UE) 2016/343 y (UE) 2016/800. - 3. ENJUICIAMIENTO EN AUSENCIA DE MENORES ACUSADOS EN EL ORDENAMIENTO JURÍDICO ESPAÑOL: 3.1. Normativa aplicable. 3.2. Inexistencia de uniformidad en la interpretación de la normativa aplicable y pasividad del legislador. 4. IDENTIFICACIÓN DEL LÍMITE IMPUESTO POR LA CLÁUSULA DE”NO REGRESIÓN", PREVISTA EN LA DIRECTIVA (UE) 2016/800, A UNA FUTURA INCORPORACIÓN DEL ENJUICIAMIENTO EN AUSENCIA DE MENORES AL SISTEMA PROCESAL PENAL ESPAÑOL: 4.1. Planteamiento del problema: cláusula de “no regresión" de la Directiva (UE) 2016/800 como obstáculo a la iniciativa 
legislativa nacional. 4.2. Una posible respuesta: análisis de la naturaleza y finalidad de la cláusula de"no regresión" de la Directiva (UE) 2016/800._CONCLUSIONES. -FUENTES CITADAS.

\section{INTRODUCCIÓN}

El enjuiciamiento en ausencia del acusado por delitos pasa a formar parte del vigente sistema procesal penal español a partir de la entrada en vigor de la LO 7/1988. Su ámbito de aplicación se limita a un tipo de proceso penal, el procedimiento abreviado, siempre que concurran además las condiciones legalmente establecidas: citación conforme a las formalidades legales, solicitud de parte acusadora para la celebración del juicio, audiencia e intervención de la defensa en el juicio a través de asistencia letrada, existencia de elementos suficientes para el enjuiciamiento y solicitud máxima de dos años de pena privativa de libertad o, de seis, si es de otra naturaleza. En el supuesto de que la ausencia sea injustificada, se prevé que el condenado pueda solicitar la rescisión de la sentencia de condena. Con excepción de la condición relativa a la gravedad de la pena solicitada, sobre la cual el TEDH no se ha pronunciado como límite al enjuiciamiento en ausencia, la previsión legal descrita se adecua a los estándares de protección del derecho a un juicio equitativo formulados por el Tribunal de Estrasburgo al interpretar el art. 6.1 CEDH.

Otra de las condiciones sobre las que tampoco ha incidido el TEDH, en el sentido de impedir o supeditar el enjuiciamiento en ausencia a la existencia de algún requisito adicional, es la minoría de edad de la persona acusada. En nuestro ordenamiento jurídico, la LO 5/2000 no prevé que la fase de audiencia pueda celebrarse en ausencia del menor acusado, pero tampoco lo prohíbe. Esta circunstancia, unida al carácter supletorio de la regulación del procedimiento abreviado respecto de los trámites establecidos en la LO $5 / 2000$, ha provocado una profunda y enraizada división en la jurisprudencia acerca de si en el proceso penal de menores, dándose las condiciones exigidas por el TEDH y asumidas por la LECrim, puede celebrarse y es válido el juicio a pesar de no haber comparecido personalmente el menor acusado.

La discrepancia jurisprudencial ha generado y continúa provocando una acentuada inseguridad jurídica, así como una discriminación entre menores acusados en función del lugar de perpetración del delito. De ahí que resulte difícil comprender el motivo por el cual todavía no se ha elaborado ninguna iniciativa legislativa que aborde, de manera fundamentada y decidida, la cuestión.

Este estudio parte de la hipótesis de que resulta ajustado no solo a los postulados del derecho a un juicio equitativo, sino también al interés superior del menor, la celebración de la audiencia en su ausencia, en especial, si es voluntaria e inequívoca, y está rodeada de las garantías procesales comúnmente aceptadas por el TEDH, el derecho de la UE y la legislación española. 
Por esta razón, su punto de partida es la jurisprudencia del TEDH sobre el derecho del acusado a estar presente en el juicio, si es o no un derecho renunciable y los requisitos que, en su caso, han de ser observados por la renuncia. En segundo lugar, se examina el alcance de su recepción por el derecho de la UE en dos campos distintos, aunque unidos en el destino de consolidar el espacio de libertad, seguridad y justicia, es decir, la cooperación judicial y la aproximación de legislaciones. Una vez constatada, la influencia del precedente en la legislación de la UE que, por otro lado, está impuesta por el art. 52.3 CDFUE, se expone la intensidad y las repercusiones de la divergencia existente, en la actualidad, en los tribunales españoles competentes sobre la corrección jurídica de la celebración del juicio en ausencia del menor acusado. Entendiendo que la divergencia solo puede ser superada con una reforma legal que, sin menoscabar el derecho del menor a estar presente y participar en el propio juicio, prevea su enjuiciamiento en ausencia, el estudio finaliza con el análisis y la valoración del posible límite a la autonomía legislativa nacional que puede venir impuesto por la cláusula de"no regresión"incluida en la Dir. 2016/800.

\section{ENJUICIAMIENTO EN AUSENCIA EN LA JURISPRUDENCIA DEL TRIBUNAL EUROPEO DE DERECHOS HUMANOS}

Para el TEDH, aun cuando no está incluido literalmente en el art. 6 CEDH, el derecho del acusado a estar presente y participar en el proceso penal constituye una faceta esencial del derecho a un juicio equitativo. Fundamenta su opinión en que sería contrario no solo a la equidad, sino también a la propia sistemática del citado precepto, minimizar la relevancia de aquel derecho, pues entonces no tendría sentido la imposición, en su apartado tercero, de unas garantías procesales mínimas, que el acusado ha de tener la oportunidad de ejercitar, consistentes en: ser oído personalmente, ser asistido por un intérprete, defenderse por sí mismo, exponer los argumentos que convengan a sus intereses, rebatir las alegaciones formuladas por las acusaciones e interrogar o hacer interrogar a los testigos tanto a los que declaren en su favor como en su contra. En otras palabras, el reconocimiento al acusado de la facultad de participar en las vistas y audiencias se erige en el objeto y la finalidad de todas las normas incluidas en el art. $6 \mathrm{CEDH}^{1}$.

1 Vid., entre otras SSTEDH, Hermi c. Italia (2006) y Arps c. Croacia (2016). 


\subsection{Compatibilidad con el derecho a un proceso equitativo de la renuncia a comparecer en el propio juicio}

Afirmada con rotundidad la importancia, en el sistema instaurado por el art. $6 \mathrm{CEDH}$, del derecho del acusado a estar presente y participar en el proceso penal, el TEDH también ha precisado que "ni la letra ni el espíritu" del citado precepto impiden que aquel renuncie "de buen grado"a las garantías de un proceso equitativo. Asimismo, ha reconocido que la imposibilidad de celebrar el juicio en ausencia del acusado, y las consiguientes suspensiones de los actos procesales, puede favorecer la pérdida de fuentes de prueba y la comisión de errores judiciales. En consecuencia, ha declarado que celebración del juicio y la condena del acusado en ausencia no comportan, de manera ineludible, la vulneración de los postulados del citado precepto ${ }^{2}$.

A raíz de dichos pronunciamientos, el TEDH se ha visto obligado a delimitar las condiciones que han de exigirse a la renuncia para que, de un lado, no se infrinja la equidad del juicio celebrado en ausencia y, de otro, la negativa del sistema procesal penal interno a reabrir un nuevo proceso no comporte una flagrante denegación de justicia. Un análisis detenido de las resoluciones dictadas al respecto, permite extraer las tres condiciones esenciales que ha de reunir la renuncia para que sea válido el enjuiciamiento en ausencia: ha de ser inequívoca, ha de estar acompañada de salvaguardas suficientes y no ha de enfrentarse a ningún interés público relevante ${ }^{3}$. Estos requisitos han sido explicados, con cierta amplitud, por el TEDH.

Cuando profundiza en la exigencia de que la renuncia sea inequívoca, el TEDH se muestra favorable a admitir tanto la explícita como la implícita. La realidad de esta última la infiere, básicamente, de los hechos que figuran en las actuaciones. Tales hechos documentados pueden revelar, por ejemplo, que el acusado conocía que se estaba tramitando un proceso penal en el que era investigado, que se le había informado de la causa y la naturaleza de la acusación y que, pese a todo, no quería participar en el juicio o que intentaba evitar su enjuiciamiento. Podía, en consecuencia, prever razonablemente que el juicio se celebraría en su ausencia y que cabía la posibilidad de que fuera condenado ${ }^{4}$.

En lo atinente a las salvaguardas que han de rodear la renuncia, el TEDH es exigente en su observancia ya que suele subrayar la gravedad de un posible resultado, esto es, la condena del acusado sin que haya estado presente en el

2 Como ha señalado Cedeño Hernán (2010, p. 286), aportando sentencias claves del TEDH, el juicio en ausencia per se no necesariamente conlleva una lesión de las garantías básicas del CEDH.

3 Dichas condiciones de la renuncia a estar presente en el propio juicio se exponen con claridad en la STEDH Haralampiev c. Bulgaria (2012).

4 Cfr. en particular, SSTEDH Sejdovic c. Italia (2006), Lena Atanasova c. Bulgaria (2017) y Karemani c. Albania (2018). 
juicio. De ahí que, aun cuando su decisión parta de un examen del conjunto de los actos procesales realizados en el concreto supuesto que se le somete a su consideración, expone con un considerable grado de detalle aquellas salvaguardas que van a evitar que se declare que la ausencia del acusado en el juicio ha violado el art. 6.1 CEDH. Así, destaca las garantías consistentes en que la citación a la audiencia del acusado se haya hecho en persona ${ }^{5}$; el acusado haya podido prever, razonablemente, las consecuencias de su conducta delictiva, lo que implica que preste especial atención al contenido de la acusación notificada, subrayando que ha de contener una información completa de los cargos que se le imputan comprendiendo, por tanto, hechos y calificación jurídica; no deba atribuirse al acusado la carga de probar que no pretendía eludir la acción de la justicia o que su ausencia fue debida a una causa justa $^{6}$; y la subordinación de la eficacia de la renuncia expresa a la presencia del abogado del acusado en el momento procesal en que aquella tenga lugar, no siendo suficiente que el acusado sea informado de las consecuencias únicamente por el tribunal, pues, los acusados suelen ser legos en derecho de modo que no están preparados para valorar todas implicaciones jurídicas que pueden derivar de su renuncia ${ }^{7}$.

El tercer requisito al que el TEDH sujeta la eficacia de la renuncia y su compatibilidad con el derecho a un juicio equitativo radica en que aquella no contradiga ningún interés público importante. De las sentencias que se refieren al mismo puede deducirse que el interés público es, en esencia, el interés estatal en que se celebre el juicio y que en él intervenga el acusado en aras de un correcto ejercicio del ius puniendi con el fin de soslayar la impunidad de las conductas delictivas. La presencia del acusado en el juicio permitirá contrastar sus declaraciones con las emitidas por las víctimas y los testigos, facilitándose la determinación de la exactitud de las afirmaciones de aquel. De modo que al interés público se sumará el de las víctimas y sus familiares, que podrán interrogar al acusado, así como el de los testigos ${ }^{8}$.

Este último requisito al que el TEDH condiciona la eficacia de la renuncia le ha obligado a ser muy minucioso en sus apreciaciones pues, en caso contrario, el margen de discrecionalidad que concede a los Estados contratantes podría volverse en contra del sistema de garantías que, respecto del derecho a un juicio equitativo, ha ido construyendo. Es decir, con la justificación de

5 A pesar de reconocer que el art. 6 CEDH no impone un tipo específico de acto de comunicación, el TEDH subraya que la citación ha de permitir al acusado, primero, conocer la fecha, hora y lugar de celebración de la vista y, segundo, poder preparar con antelación suficiente su defensa. Cfr. SSTEDH Somogyi c. Italia (2004), M. T. B. c. Turquía (2018), Dridi c. Alemania (2018) y Vyacheslav Korchagin c. Rusia (2018).

6 Cfr. STEDH Medenica c. Suiza (2001).

7 La efectiva asistencia letrada al acusado, previa a la renuncia expresa a estar presente en el juicio, no puede ser substituida por la información que sobre las consecuencias de la renuncia pudiera proporcionarle el tribunal; vid. STEDH Pfeifer y Plankl c. Austia (1992).

8 Vid. SSTEDH Håkansson y Sturesson c. Suecia (1990) y Sejdovic c. Italia (2006). 
velar por el respeto del interés público, equiparándolo al interés estatal, se podría, de un lado, favorecer la alteración de la naturaleza de los derechos individuales consagrados en el CEDH transformándolos en obligaciones cuyo incumplimiento podría ser sancionado y, de otro, el TEDH podría tener que aceptar la compatibilidad con el derecho a un juicio equitativo de cualquier medida adoptada por los legisladores nacionales tendente a provocar un efecto disuasorio de ausencias injustificadas de los acusados en el juicio.

Con sumo cuidado, el TEDH ha ido separando las medidas desalentadoras de la ausencia voluntaria que no entran en contradicción con derecho a un juicio equitativo, como podría ser, la privación de libertad autorizada en los supuestos del art. 5.1 CEDH, de aquellas otras que ha calificado de radicalmente desproporcionadas, argumentando primero, en que en una sociedad democrática ocupan un lugar prevalente los derechos de la defensa sobre el interés público y el de las víctimas y, segundo, en que en ningún caso el reconocimiento y ejercicio de las garantías del derecho a un juicio equitativo pueden subordinarse a que el sospechoso se entregue a las autoridades de persecución criminal ${ }^{9}$. Una de estas últimas medidas establecidas en las legislaciones internas que, de acuerdo con la jurisprudencia del TEDH atentan contra el derecho a un juicio justo, es la privación al acusado ausente del derecho a ser representado y asistido por letrado en la celebración de las vistas, incluso en los supuestos en los que aquel se haya fugado y la única cuestión que deba debatirse sea meramente jurídica sin que se haya de proceder, por tanto, a la práctica de medios de prueba ${ }^{10}$.

Ahora bien, también hay que advertir que el TEDH ha relativizado los requisitos de la renuncia y ha suavizado el estricto cumplimiento por las autoridades competentes del deber de emplear la debida diligencia en la práctica de los actos de comunicación y de proporcionar una completa información tanto en lo referente a los cargos que se imputan al acusado cuanto a las consecuencias de su renuncia, ya que del incumplimiento de esos deberes no ha entendido que se deriva, inexcusablemente, la ilegalidad del juicio in absentia. En estos contextos, caracterizados por no constar de forma inequívoca la renuncia al derecho a comparecer o la intención de fuga, el TEDH ha requerido, para poder declarar que la celebración del juicio sin la presencia del acusado no es incompatible con el art. 6.1 CEDH, que se prevea el derecho del condenado a acceder a un nuevo juicio o a nuevas vías de recurso que den lugar a una nueva decisión sobre el fondo. Cumpliéndose esta condición, entiende que el proceso en su conjunto ha sido equitativo ${ }^{11}$.

9 Vid. sobre esta cuestión, BOSE (2011, pp. 500-503).

10 Vid. al respecto SSTEDH Poitrimol c. Francia (1993), Lala c. Holanda (1994), Pelladoah c. Holanda (1994); Van Geyseghem c. Bélgica (1999), Krombach c. Francia (2001), Neziraj c. Alemania (2012), Tolmachev c. Estonia (2015) y Frolovs c. Letonia (2017).

11 Cfr. entre otras muchas, SSTEDH Colozza c. Italia (1985), Jones c. Reino Unido (2003), Sejdovic c. Italia (2006), Demeboukov c. Bulgaria (2008), Aliykov c. Bulgaria 
No puede negarse que se trata de una jurisprudencia que cabe calificar de flexible en cuanto a la delimitación del alcance del derecho a participar en el propio juicio, pero que responde a una innegable realidad: la mayoría de los Estados parte del Consejo de Europa contemplan en sus ordenamientos jurídicos la posibilidad, sujeta a diversos presupuestos, de celebrar juicios sin la presencia del acusado.

Por otro lado, es una jurisprudencia que no solo ha sido aplicada en asuntos domésticos sino que se ha extendido también al ámbito de la cooperación internacional. Ha sido señalado que esta circunstancia obedece a que en el Segundo Protocolo Adicional al Convenio sobre Extradición del Consejo de Europa, de 17 de marzo de 1978 (art. 3, Capítulo III), pese a que se autoriza al Estado requerido a denegar la extradición de la persona juzgada en ausencia cuando entiende que en el procedimiento seguido en el Estado requirente no se han respetado los mínimos derechos de defensa que deben ser garantizados a cualquier acusado, no obstante debe proceder a la extradición en el supuesto de que el Estado requirente asegure que el condenado puede solicitar la celebración de un nuevo juicio en el que van a ser salvaguardados sus derechos de defensa ${ }^{12}$.

A nuestro entender, solo cabría añadir que la doble esfera en la que opera la jurisprudencia del TEDH sobre el derecho a estar presente y a participar en el propio juicio, es decir, la puramente nacional y la internacional, es coherente con la política adoptada por el Consejo de Europa respecto a los juicios penales celebrados en ausencia y que se plasma, entre otros documentos, en la Resolución (75) 11, sobre los criterios a seguir en el enjuiciamiento en ausencia del inculpado, aprobada por el Comité de Ministros el 21 de mayo de 1975. El motivo principal que desencadena la necesidad de elaborar tales criterios es la reacción adversa de varios Estados parte a la normativa reguladora de la ejecución, en un Estado distinto del Estado en que se haya dictado una sentencia de condena en ausencia del acusado, prevista en el Convenio Europeo sobre el valor internacional de las sentencias penales de condena, de 28 de mayo de 1970. De manera que tras admitir que "una unión más estrecha" entre los Estados parte del Consejo de Europa en dicho ámbito no puede lograrse por la vía de dar por existente una confianza recíproca, la Resolución (75) 11 formula unas "normas mínimas" cuya observancia "recomienda" a los gobiernos nacionales, seguramente, con el convencimiento de que la aproximación legislativa puede poner fin a las reservas de los Estados parte al sistema instaurado por el Convenio de 1970.

(2009), Faniel c. Bélgica (2011), Mihelj c. Eslovenia (2015), Sanader c. Croacia (2015), Hokkeling c. Holanda (2017) y K. c. Albania (2018).

${ }^{12}$ Un ejemplo de la extensión de la jurisprudencia del TEDH sobre el derecho a participar en el propio juicio al campo de la cooperación internacional se halla en la decisión de inadmisibilidad dictada en el asunto Battisti c. Francia (2006). Vid. sobre este tema, Ruggeri (2019, pp. 586-591). 
La Resolución (75) 11 parte de la premisa de la adecuación al CEDH del enjuiciamiento penal en ausencia, aun cuando, restringido a las infracciones leves y siempre que se incorporen a los ordenamientos nacionales las "normas mínimas" que relaciona, entre las que cabe destacar las siguientes: los medios de prueba deben practicarse según las reglas comunes teniendo la defensa el derecho a intervenir en dicha práctica; el condenado en ausencia debe poder impugnar la sentencia a través de todos los recursos que hubiera podido interponer si hubiera comparecido; el condenado en ausencia, si no ha sido regularmente citado, ha de poder disponer de una vía procesal para que se declare la nulidad de la sentencia y, si ha sido correctamente citado, tiene derecho a ser juzgado de nuevo en la forma ordinaria en el supuesto de que acredite, que su ausencia y el hecho de no haberla puesto de manifiesto al órgano judicial, se debieron a causas ajenas a su voluntad.

\subsection{Particularidades del enjuiciamiento en ausencia en segunda instancia}

En todos los supuestos en los que el TEDH ha debido pronunciarse sobre el derecho del acusado a personarse en la vista de la segunda instancia, este ha recordado que constituye una vertiente esencial del derecho a un juicio equitativo pero, a continuación, ha precisado que es un derecho de índole general que puede ser matizado teniendo en cuenta las particularidades del concreto sistema de justicia penal involucrado. Y la matización más importante que efectúa es, a nuestro entender, la que incide en subrayar que la presencia del acusado no tiene en la vista de la segunda instancia la misma relevancia que en la celebrada en primera instancia ${ }^{13}$.

Habiendo estado presente el acusado en la vista celebrada en primera instancia, el TEDH ha declarado que la inexistencia de un debate contradictorio en segunda instancia a causa de la ausencia del acusado no infringe de plano el derecho a un juicio equitativo. Su vulneración depende del resultado que arroje el examen de los aspectos siguientes: las características del sistema de apelación nacional, la extensión de los poderes del tribunal de segunda instancia, la manera en que los intereses del acusado han sido expuestos y salvaguardados en segunda instancia y, principalmente, el carácter de las cuestiones sobre las que se ha de pronunciar el tribunal de apelación. Respecto de este último extremo, ha puntualizado que la celebración de la vista no es indispensable si la decisión del tribunal de apelación sobre la culpabilidad del acusado se ha basado en un análisis de cuestiones puramente jurídicas, sin abordar los hechos singulares de la causa apelada ${ }^{14}$. Por el contrario y como

13 Cfr., en especial, STEDH Hermi c. Italia (2006).

14 Cfr., entre otras, SSTEDH Delcourt c. Bélgica (1970), Botten c. Noruega (1996), Spînu c. Rumanía (2008), Bazo González c. España (2008), Valbuena Redondo c. España (2011), Hernández Royo c. España (2016) y Pardo Campoy y Lozano Rodríguez c. España (2020). 
regla general, sí es necesaria la presencia del acusado cuando el tribunal de segunda instancia deba pronunciarse sobre la culpabilidad o inocencia del acusado analizando tanto los hechos como el derecho aplicable ${ }^{15}$.

Sin embargo, la naturaleza fáctica o jurídica del motivo en el se funda el recurso de apelación no siempre es la clave que permite establecer la compatibilidad de la ausencia del acusado en la vista de la segunda instancia con el derecho a un juicio equitativo. En efecto, para el TEDH no es imprescindible la presencia del acusado si las cuestiones que plantea en apelación, tanto las fácticas como las jurídicas, pueden ser resueltas mediante un examen del expediente o si la sentencia de apelación no puede aumentar la pena impuesta en primera instancia ${ }^{16}$. De ello se deriva que, en tales supuestos, la apelación debe sustanciarse aun cuando la ausencia del acusado sea no solo voluntaria sino también injustificada, lo que a su vez comporta que si su abogado comparece a la vista ha de poder ejercer la defensa puesto que es contrario a lo dispuesto en el art. 6.3.c) CEDH prohibirle que intervenga con base en aquella ausencia

Con respecto a la asistencia letrada, a la que se ha hecho una breve referencia en el epígrafe anterior, el TEDH ha elaborado una doctrina uniforme y constante según la cual la equidad de un sistema de justicia penal se halla condicionada a que el acusado, tanto en primera como en segunda instancia, pueda ejercer su derecho a la defensa, en especial, a través de la asistencia jurídica que le preste un abogado de su confianza. A dicha asistencia le concede una importancia crucial, pues, ha sostenido sin fisuras que el acusado no debe ser privado de la misma aunque no comparezca en el juicio habiendo sido citado de conformidad con las previsiones legales y no habiendo invocado ningún tipo de motivo que justifique su ausencia. Es más, ha precisado que el derecho a ser efectivamente defendido por letrado, bien de libre designación bien nombrado de oficio, es un componente fundamental del derecho a un juicio equitativo, concluyendo que su ejercicio no tiene como presupuesto la comparecencia personal del acusado en el proceso.

La rotundidad con la que el TEDH se ha expresado al respecto es un factor a tener en cuenta, en especial, si se observa que en sus razonamientos no deja de valorar el interés público, así como el de las víctimas, en que el acusado esté presente en la vista a los efectos de que el tribunal de segunda instancia pueda verificar la credibilidad de sus declaraciones, confrontarlas con las emitidas por las víctimas y testigos, cumplir con su deber de averiguar la verdad e imponer una pena justa. Como resultado acepta que un sistema de justicia penal arbitre medidas que fomenten la presencia de los acusados

15 Cfr., en este sentido, SSTEDH Ekbatani c. Suecia (1988), Constantinescu c. Rumanía (2000) y Styrmir Pór Bragason c. Islandia (2019).

16 Cfr., por ejemplo, SSTEDH Fejde c. Suecia (1991), Botten c. Noruega (1996) y Seliwiak c. Polonia (2009). 
a las vistas y audiencias. Ahora bien, tales medidas deben dejar incólume el derecho a la asistencia letrada ${ }^{17}$.

\section{ENJUICIAMIENTO EN AUSENCIA EN INSTRUMENTOS NORMATIVOS DE LA UNIÓN EUROPEA Y SU INTERPRETACIÓN POR EL TJUE}

\subsection{Recepción de la jurisprudencia del TEDH en las Decisiones marco 2002/584/JAI y 2009/299/JAI}

Por lo que se refiere a la UE, el primer instrumento normativo en el que se recoge la jurisprudencia indicada del TEDH sobre el derecho del acusado a participar en el juicio, es la Decisión marco 2002/584/JAI. La aplicación del principio de reconocimiento mutuo con vistas a hacer posible la ejecución de resoluciones dictadas en otro Estado miembro en juicios celebrados sin

17 Uno de los sistemas de justicia penal que se ha visto interpelado y afectado por la doctrina examinada, que como se ha subrayado mantiene la vigencia de la garantía de la asistencia letrada aun en los supuestos en los que el acusado de forma deliberada e injustificada evita estar presente en el propio juicio, es el alemán. El TEDH en la sentencia dictada en el asunto Neziraj c. Alemania (2012) tuvo que analizar la compatibilidad de la regulación de la segunda instancia prevista en la Ley procesal penal alemana (StPO) con el derecho a un juicio equitativo consagrado en el CEDH. El demandante alegó la vulneración de esos derechos al haber el tribunal de apelación alemán desestimado su recurso, sin entrar en el fondo, motivando su decisión en que aquel no asistió a la vista. El acto procesal trascendente de ese asunto radicó en que el tribunal de apelación no permitió que el abogado del demandante, que sí compareció y estaba dispuesto a ejercer la defensa, interviniera en la vista. Para el TEDH tal prohibición supuso la violación del derecho a un juicio equitativo en conjunción con el derecho a la defensa letrada consagrados en el CEDH. Esta resolución del TEDH generó una oposición por parte de los tribunales alemanes al entender estos últimos que el art. 6.3.c) CEDH no imponía que los intereses del acusado en el procedimiento de apelación estuvieran representados por abogado. En concreto, el Tribunal Constitucional alemán, en su sentencia de 27 de diciembre de 2006, entendió que el tribunal de apelación en ese asunto no vulneró el derecho de defensa pues este debía ser interpretado en el contexto del modelo alemán de recurso de apelación, concebido como un nuevo juicio tanto respecto de cuestiones fácticas como jurídicas, con amplias posibilidades de práctica de medios de prueba, por lo que sus trámites han de adecuarse al principio de inmediación. Tal rechazo no logró evitar que el legislador alemán tuviera que modificar uno de los preceptos reguladores del recurso de apelación con el fin de acomodarlo a la jurisprudencia del TEDH. Nos referimos al §329 StPO cuya reforma ha tenido por objetivo que la apelación pueda ser sustanciada in absentia, siempre que la presencia del acusado no sea necesaria para descubrir la verdad y aquel esté representado por un letrado (Gesetz zur Stärkung des Rechts des Angeklagten auf Vertretung in der Berufsverhandlung und ubre die Anerkennung von Abwesenheitsentscheidungen in der Rechtshilfe, de 17 de julio de 2015). Vid. sobre este interesante tema Ambos (2017, pp. 169-171) y Vogel (2019, pp. 140-142 y 157-159). 
comparecencia del condenado, obligó a prever tal supuesto. Y se hizo, por un lado, asumiendo que podía darse el caso de que el condenado en ausencia no hubiera sido citado personalmente o informado de otra manera de la fecha y lugar de celebración del juicio y, por otro, permitiendo que, en dicho supuesto, la autoridad judicial de ejecución supeditara la entrega de aquel a la condición de que se garantizara de forma suficiente la celebración de un nuevo proceso en el Estado miembro de emisión de la ODE con la presencia de aquel en la vista (art. 5.1). De modo que, puede decirse que la Decisión marco 2002/584/JAI se limitó a incorporar a su articulado la circunstancia que con carácter excepcional admite el TEDH de celebración del juicio en ausencia (la ausencia involuntaria) y el estándar mínimo de protección formulado para esa circunstancia (la posibilidad de pedir un nuevo proceso en el Estado emisor en el que estuviera previsto, entre otros, el ejercicio del derecho a estar y participar en el juicio).

Las diferentes interpretaciones del alcance del art. 5.1 por las autoridades nacionales competentes, tanto de emisión como de ejecución de una ODE, debidas, principalmente, a la diversidad de regulaciones nacionales sobre el enjuiciamiento en ausencia del acusado y las garantías que debían rodearlo, así como, a los distintos significados que se atribuyeron a la situación jurídica de "rebeldía", impidió que hubiera una opinión común acerca de si era ajustado a lo dispuesto en el citado artículo que la autoridad judicial del Estado de ejecución condicionara, incluso en supuestos de ausencia voluntaria, la detención y entrega de la persona reclamada a que esta tuviera la posibilidad de pedir que se celebrara, en el Estado de emisión, un nuevo proceso en el que se salvaguardaran sus derechos a la defensa y a estar presente en la vista.

Con la intención de superar esa situación de inseguridad jurídica y, sobre todo, de evitar que quedara en manos de la autoridad judicial de ejecución un excesivo grado de discrecionalidad a la hora de decidir si se daba el supuesto de hecho para exigir garantías a la autoridad judicial de emisión de la posibilidad de que la persona reclamada volviera a ser juzgada, se aprobó la Decisión marco 2009/299/JAI que modifica, junto a otras decisiones marco, la Decisión marco 2002/584/JAI, para reforzar los derechos procesales de las personas y propiciar la aplicación del principio de reconocimiento mutuo de las resoluciones dictadas a raíz de juicios celebrados sin comparecencia del imputado $^{18}$.

La reforma operada sobre la Decisión marco 2002/584/JAI suprime el art. 5.1 y añade un nuevo precepto, el 4 bis donde se fijan las condiciones en las que no deberá denegarse ni el reconocimiento ni la ejecución de las resoluciones dictadas en juicios celebrados sin la comparecencia del imputado. Estas condiciones son ya un reflejo más exacto de las circunstancias que, según el TEDH, pese a haberse celebrado el juicio en ausencia no suponen una

18 Sobre los motivos que justificaron la adopción de la Decisión marco 2009/299/ JAI, vid. entre otros, Jimeno Bulnes (2011b, pp. 169-172); Cedeño Hernán (2010, pp. 289-296) y Gutiérrez Berlinches (2009, pp. 170 y 171). 
violación del art. $6 \mathrm{CEDH}$, bien porque la persona condenada en ausencia fue informada personalmente o tenía conocimiento de la celebración del juicio y de sus consecuencias, de modo que se entiende que ha renunciado voluntaria e inequívocamente a su derecho a comparecer; bien porque aun cuando no fue informada o no tuvo conocimiento previo de la celebración del juicio, al serle notificada la sentencia de condena se le informó sobre su derecho a un nuevo juicio o a interponer un recurso en el que volverán a examinarse los argumentos presentados en el juicio en ausencia, así como los posibles nuevos elementos probatorios ${ }^{19}$.

La mayor precisión en la configuración de las condiciones, en las que no puede denegarse la ejecución de una ODE, no busca solo propiciar la aplicación del reconocimiento mutuo de resoluciones dictadas en ausencia del imputado y facilitar la cooperación judicial penal, sino que, como establece la Decisión marco 2009/299/JAI en su art. 1.1 y considerando 15, también pretende reforzar los derechos procesales de las personas acusadas, en particular el derecho a un juicio equitativo. A este objetivo se refieren las sentencias del TJUE que han interpretado alguno de los conceptos jurídicos autónomos que forman parte del supuesto de hecho del art. 4 bis Decisión marco 2002/584/JAI al dejar claro que, potenciando la virtualidad del principio de reconocimiento mutuo mediante la armonización de las condiciones en las que debe procederse al cumplimiento de las órdenes de detención emitidas para la ejecución de las resoluciones dictadas en ausencia, se incide irremediablemente en los derechos procesales fundamentales de las personas afectadas, de modo, que por obra del art. 52.3 CDFUE la protección que el Derecho de la UE concede a los mismos ha de ser más extensa que la otorgada en el $\mathrm{CEDH}^{20}$.

19 El TEDH ha tenido la oportunidad de pronunciarse, en la sentencia dictada en el asunto Pirozzi c. Bélgica (2018), sobre las garantías que para la efectividad del derecho a un juicio equitativo (art. 6.1 CEDH) representan las circunstancias establecidas en el art. 4 bis Decisión marco 2002/584/JAI que impiden a la autoridad competente denegar la ejecución de una ODE basada en una condena dictada en ausencia del acusado. Es cierto que dicha sentencia se origina en una demanda que pone en tela de juicio el grado del control que la autoridad de ejecución ha de llevar a cabo en orden a ejecutar una ODE. De modo que el extremo principal, que el TEDH aborda en el citado asunto, estriba en determinar si en el supuesto de que el sistema de la ODE comportara, inexorablemente, la aplicación de una presunción automática de protección equivalente de derechos fundamentales, que eliminara el poder discrecional de la autoridad de ejecución, podría ser contrario al derecho a un juicio equitativo consagrado en el CEDH. Sin embargo, su análisis va más allá de ese extremo, pues, no solamente concluye, con carácter general, que el principio de reconocimiento mutuo no debe aplicarse automáticamente y en detrimento de los derechos fundamentales, sino que además añade que la ejecución de la ODE dictada para la entrega de una persona condenada en ausencia, en un proceso en el que se han dado alguna de las condiciones previstas en el art. 4 bis Decisión marco 2002/584/JAI, es respetuosa con los derechos garantizados por el CEDH.

20 Cfr. al respecto SSTJUE Melloni (2013), Dworzecki (2016), Tupikas (2017), Zdziaszek (2017) y Ardic (2017). 


\subsection{Continuidad en la regulación del enjuiciamiento en ausencia en las Directivas (UE) 2016/343 y (UE) 2016/800}

Es en este entorno tan complejo, formado por la interacción del principio de reconocimiento mutuo con la aproximación de legislaciones, en el que se adoptan las Directivas 2016/343 y 2016/800. Este hecho puede explicar el enfoque que dan a la celebración de juicios en ausencia del acusado ${ }^{21}$. Las citadas Directivas se mantienen en la línea de la jurisprudencia del TEDH y de las Decisiones marco de 2002 y 2009, pues requieren a los Estados miembros que prevean las condiciones y garantías para que los acusados puedan ejercitar su derecho a estar presente en el propio juicio; derecho al que pueden renunciar, de modo que cabe que el juicio en el que se declara su responsabilidad penal se celebre en su ausencia ${ }^{22}$. Por lo que se refiere a las garantías que pueden compensar el menoscabo que experimenta el derecho de defensa, y que permiten sostener que a pesar de la ausencia del menor acusado el juicio ha sido equitativo, la Dir. 2016/800, solo alude en el texto articulado de forma muy laxa al derecho que se le debe reconocer a un nuevo juicio o a otro tipo de recurso judicial (art. 16.2) y en sede de considerandos precisa que, si bien el menor debe ser citado a juicio en persona, ha de enviarse una copia de la citación al titular de la potestad o, si fuera contrario al interés del menor, a otra persona adulta que se estime adecuada (c. 60). No contempla ninguna mayor concreción ni ningún otro estándar de protección del derecho a estar presente en el propio juicio ${ }^{23}$. De modo que, en lo atinente a los supuestos en los que los menores condenados sean sujetos pasivos de una ODE, el régimen jurídico que regirá su ejecución será el establecido en la Decisión marco de 2009 y, para la concreta regulación de los estándares mínimos que prote-

21 Ambas Directivas son el resultado de la iniciativa de la Comisión que cumplió con el mandato político, establecido en el Programa de Estocolmo, de presentar propuestas tendentes a incrementar los actos legislativos sobre normas mínimas relativas a derechos procesales de sospechosos y acusados en los procesos penales -COM(2013) 820 final, de 27 de noviembre de 2013-. Se optó, como en la Resolución del Consejo de 30 de noviembre de 2009, cuyo plan de trabajo había sido prácticamente completado, por un abordaje gradual de algunos derechos y garantías procesales, entre ellos, ciertos aspectos de la presunción de inocencia, el derecho a estar presente en los procesos penales y las garantías especiales de los menores sospechosos o acusados en los procesos penales.

22 Vid. en relación con la Directiva (UE) 2016/343, entre otros, Villamarín López (2017, pp. 28 y 29), Arangüena Fanego (2019, pp. 24-27), Bachmaier Winter (2019, pp. 656-658), Guerrero Palomares (2018, pp. 143-175), Cras y Erbežnik (2016, pp. 2536) y Ruggeri (2016, pp. 42-51). Con respecto a la Dir. 2016/800, vid. entre otros, González Pillado (2019, pp. 59-97), Cras (2016, pp. 109-120) y Serrano Masip (2016, pp. 211-263).

${ }^{23}$ Es decir, el legislador UE a pesar afirmar en el c. 43 Dir. 2016/343 que "los menores son vulnerables y deben recibir un grado específico de protección" no ha previsto, en la Dir. 2016/800, un conjunto de garantías específicas del derecho a estar presente en el juicio en el que se incluyera, por ejemplo, la forma de renunciar al mismo. 
gen de forma suficiente a los menores acusados que son juzgados en ausencia, deberá estarse a las disposiciones de la Dir. 2016/343.

Este último instrumento normativo, cuando aborda en sus arts. 8 y 9 la regulación del derecho a estar presente en el juicio, si bien en primer lugar ordena a los Estados miembros que garanticen a los sospechosos y acusados la efectividad de aquel derecho, en segundo término transforma aquellas garantías en condiciones legitimadoras de la celebración del juicio en ausen$\mathrm{cia}^{24}$. Así, autoriza a aquellos Estados a prever la celebración del juicio en ausencia del acusado y la ejecución de la sentencia de condena que, en su caso sea dictada, siempre que este haya sido oportunamente informado del juicio y de las consecuencias de su incomparecencia, o tras haber sido informado del juicio, esté formalmente defendido por un letrado de libre elección o de oficio. Pero todavía debe señalarse que la autorización va más allá, pues de conformidad con la jurisprudencia expuesta del TEDH, la celebración del juicio en ausencia, cuando el acusado no haya sido informado ni de su conducta pueda inferirse una renuncia voluntaria e inequívoca a estar presente en el juicio, no es incompatible con el derecho a un juicio equitativo consagrado en el art. 47 CDFUE con tal que con posterioridad se le informe acerca de la resolución dictada y de su derecho a impugnarla o a un nuevo juicio en el que ha de tener lugar una nueva apreciación del fondo del asunto, incluido el examen de nuevas pruebas, que puede concluir con la revocación de la resolución original.

Aunque resulta claro que la Dir. 2016/343 pretende que los Estados miembros de la UE aproximen sus legislaciones con respecto a los requisitos procesales en los que la Decisión marco 2009/299/JAI justifica el reconocimiento de una sentencia de condena dictada en ausencia a los efectos de ejecutar una ODE, si se comparan los arts. 8 Dir. 2016/343 y 4 bis.1 Decisión marco 2002/584/JAI se observa que las garantías relativas a las formalidades de la citación a juicio son menos exigentes en el primer precepto que en el segundo. Pese a ello, se ha señalado que el TJUE debería interpretar las disposiciones de la Dir. 2016/343 relativas al derecho a estar presente en el propio juicio de conformidad con su jurisprudencia sobre el art. 4 bis.1 Decisión marco 2002/584/JAI ${ }^{25}$.

Por el momento, la STJUE dictada en el asunto TX y UW (2020) es la primera que interpreta un precepto regulador del derecho a estar presente en el juicio, art. 8, apartados 1 y 2, así como algunos considerandos de la Dir. 2016/343. En ella se resuelve una cuestión prejudicial planteada por un tribunal penal búlgaro que no tiene la certeza de que en el proceso que está tramitando se haya respetado, a dos acusados a los que se atribuye la perpetración de delitos graves, el derecho a participar personalmente en el mismo, pues, algunas sesiones se han celebrado en su ausencia. El tribunal

${ }^{24}$ Cfr. Schneider (2019, pp. 608-610).

25 Cfr. Brodersen, Glerum y Klip (2020, p. 67). 
remitente solicita al TJUE que le aclare si la aplicación de las normas de la Ley de enjuiciamiento criminal búlgara que permiten el enjuiciamiento en ausencia y los actos procesales que ha adoptado interpretándola infringen el derecho de los acusados a estar presentes en el juicio y, si la respuesta es que se ha producido una vulneración del derecho indicado, interesa que le haga saber cuáles son las medidas adecuadas para poner remedio a tal infracción.

Se trata de una cuestión prejudicial cuyo origen se halla en la celebración de unas vistas de un proceso penal en las que confluyen una ausencia voluntaria y otra involuntaria. De modo que en el marco de dicho proceso, el tribunal nacional ha de examinar, de un lado, si concurren los requisitos que ha de cumplir la renuncia de un acusado para que se estime que la ausencia es voluntaria sin que se invaliden los actos procesales practicados con posterioridad y, de otro, si los actos procesales que se reputan ineficaces, pues han sido ejecutados estando un acusado en situación de ausencia involuntaria, pueden ser subsanados mediante la realización de ulteriores actos procesales ${ }^{26}$.

El planteamiento relativo a la ausencia voluntaria gira en torno a la duda acerca de si las garantías procesales previstas en la normativa nacional, que comportarían que la renuncia fuera válida al no menoscabar el derecho a estar presente en el juicio, son o no compatibles con lo dispuesto en la Dir. 2016/343.

Por lo que se refiere a la Ley de enjuiciamiento criminal búlgara, el proceso penal en ausencia puede celebrarse siempre que el acusado sea informado de la sustanciación del juicio y de las consecuencias de su incomparecencia, debiendo además estar representado por un abogado. A su vez, como ya ha sido expuesto, la Dir. 2016/343 no es contraria a que, concurriendo "determinadas circunstancias" pueda tramitarse un proceso penal, en ausencia de la persona sospechosa o acusada, desde su inicio hasta que finalice por sentencia condenatoria o absolutoria. A estas "determinadas circunstancias" aluden varios de sus considerandos con distinta precisión, claridad y amplitud, permitiendo

${ }^{26}$ La cuestión prejudicial se formula en los términos siguientes: “¿Se vulnera el derecho del acusado a estar presente en el juicio con arreglo a lo dispuesto en el artículo 8, apartados 1 y 2, de la Directiva 2016/343, en relación con sus considerandos 35 y 44 , si una de las sesiones en un proceso penal se celebra en ausencia del acusado y este había sido debidamente convocado, informado de las consecuencias de su incomparecencia y defendido por el abogado de su elección, cuando:

a) no compareció por razones no ajenas a su voluntad (es decir, cuando decidió no asistir a la sesión en cuestión);

b) no compareció por una razón ajena a su voluntad (a saber, una enfermedad), si a continuación fue informado de los actos realizados en su ausencia y, conocedor de la situación, decidió y declaró que:

- no cuestionaría la legalidad de dichos actos invocando su incomparecencia y que no deseaba que se repitiesen en su presencia;

- deseaba participar en dichos actos, de modo que el órgano jurisdiccional llevó a cabo un segundo interrogatorio de la persona indicada por el acusado, dando a este la posibilidad de participar plenamente en dicho interrogatorio?". 
distinguir tres categorías de "circunstancias": la primera referente a la información que ha de recibir el acusado, la segunda centrada en las formas y el carácter que ha de revestir la renuncia al derecho a estar presente en el propio juicio y la tercera relativa a una vertiente del derecho de defensa que es la intervención en el juicio de un letrado que defienda los intereses del acusado ausente ${ }^{27}$. Todas estas "circunstancias" alcanzan el rango de derecho positivo al estar contempladas en el art. 8 Dir. 2016/343. En cuanto al contenido de la información, esta ha de tener por objeto la futura celebración del juicio y las consecuencias de la incomparecencia, en particular, que puede pronunciarse una resolución sin que el acusado haya comparecido. Respecto a la renuncia al derecho a estar presente en el propio juicio puede ser expresa o tácita pero siempre ha de ser inequívoca. Y, finalmente, la intervención del letrado, bien designado por el acusado bien nombrado de oficio, es preceptiva.

Tras comparar ambas regulaciones, y examinar cómo se ha aplicado la normativa interna, el TJUE concluye que en el litigio principal se cumplieron los requisitos establecidos en el art. 8.2.a) y b), así como, que la renuncia estuvo rodeada de un mínimo de garantías, conformes a la gravedad de los hechos imputados, y sin que se contradijera ningún interés público importante, ya que la presencia de los acusados no se estimó necesaria para esclarecer la verdad objetiva. Por todo ello, declara que el art. 8.2 Dir. 2016/343 no se opone a una normativa nacional según la cual no se vulnera el derecho del acusado a estar presente en el juicio cuando este haya decidido, inequívocamente, no comparecer en una de las vistas del juicio con tal que haya sido, oportunamente, informado del juicio y haya estado, formalmente, defendido en dicha vista por un letrado de libre designación (apdos. 39 a 42).

El planteamiento referente a la ausencia involuntaria surge de la incertidumbre relativa a la compatibilidad con la Dir. 2016/343 de la subsanación que tuvo lugar en el litigio principal de actos procesales que podrían haber sido declarados ineficaces, pues, fueron practicados sin estar presente en la sesión del juicio uno de los acusados por causa ajena a su voluntad. La convalidación tuvo lugar a través de dos vías: la primera radicó en otorgar eficacia a la renuncia del acusado a que se repitieran determinados actos previos realizados en una de las sesiones del juicio y la segunda consistió en acceder a la petición del acusado de repetir algunos de los actos procesales practicados en otra sesión. No obstante, para el tribunal remitente es dudoso que la renuncia al derecho a estar presente en el propio juicio pueda tener por objeto los actos efectuados ex ante. Y en lo atinente a la repetición de alguno de los actos procesales practicados en ausencia del acusado, se interroga sobre si es una medida susceptible de reparar el menoscabo que ha experimentado en su derecho a participar en esa sesión.

Respecto de la primera vía de subsanación, el TJUE afirma que la declaración del acusado ausente en la que, tras ser informado de los actos realizados

27 Cfr., en especial, considerandos 35 a 37 Dir. 2016/343. 
sin estar presente, manifestó que no invocaría la ausencia para impugnar la legalidad de los actos realizados y que no deseaba que fueran repetidos en su presencia, puede considerarse constitutiva de una renuncia inequívoca al derecho a asistir a la vista en cuestión (apdos. 45 y 46). Y, en lo atinente a la segunda vía de subsanación, el TJUE evita emitir un pronunciamiento sobre la concreta pregunta del tribunal remitente, esto es, si la repetición de alguno de los actos procesales (práctica de un medio de prueba) que tuvo lugar en la sesión en la que estuvo ausente el acusado, es una medida que puede ser englobada en el concepto de "recurso eficaz" frente a la vulneración de su derecho de defensa que manejan el art. 9 y el considerando 44 Dir. 2016/343. Así, simplemente argumenta que un acusado, que ha logrado que se repitan los actos procesales que estima relevantes para sus intereses y que fueron llevados a cabo en las vistas en las que no pudo comparecer, no ha estado ausente en el juicio (apdos. 47 y 48$)^{28}$.

Examinados los puntos clave de la sentencia dictada en el asunto $T X y$ $U W(2020)$, es conveniente poner de relieve dos extremos que constan en la misma a los que el TJUE les da escasa importancia pero que, a nuestro parecer, van a tener una interesante trayectoria en futuras resoluciones ya que ponen de manifiesto ciertas lagunas en la armonización pretendida por la Dir. 2016/343. El primero, muy ligado a las singularidades del litigio principal, se concreta en la gravedad de los delitos imputados (pertenencia a organización criminal y comisión de diversas conductas delictivas) y en la ausencia involuntaria caracterizada por su temporalidad y por la posibilidad de dar lugar a la repetición de actos procesales previos. El segundo extremo, de índole general, se refiere a las formalidades que ha de reunir el acto de comunicación al acusado de la celebración del juicio, así como, a la diligencia que han de observar, tanto las autoridades competentes cuando informan de sus derechos procesales al acusado, cuanto este último en recibir la información que se le remite.

Aun cuando se separa de lo que es, estrictamente, el objeto del presente estudio, enjuiciamiento en ausencia de menores acusados, debe incluirse en este epígrafe una reciente STJUE al ser una manifestación de lo que se acaba de afirmar sobre los problemas interpretativos que van a generar la efectividad de los derechos procesales a sospechosos y acusados en los casos de celebración de procesos penales en ausencia. La resolución aludida es la STJUE dictada en el asunto VW (2020) que interpreta unas normas de la Dir. 2013/48 otorgándoles un determinado sentido con el fin de garantizar la equidad de

${ }^{28}$ En definitiva, el TJUE viene a decir, primero, que lo que no procedía en el caso concreto era declarar la nulidad de actuaciones ya que el acusado en situación de ausencia involuntaria fue citado según lo dispuesto en la ley; segundo, que tampoco era pertinente limitar su oportunidad de reacción, frente a la infracción del derecho a estar presente y participar en el juicio, a la interposición de un recurso contra la sentencia que se dictara y, tercero, que tras su intervención en el juicio ya no puede considerarse que ha sido juzgado en ausencia. 
los actos procesales celebrados en ausencia, más correctamente en rebeldía, en la fase de instrucción del proceso penal.

La mencionada sentencia resuelve una cuestión prejudicial formulada por el Juzgado de Instrucción n. ${ }^{\circ} 4$ de Badalona y que, a nuestro entender, va a tener una gran repercusión en nuestro sistema procesal penal. Esencialmente, este Juzgado pregunta a partir de qué momento un sospechoso, que no comparece tras ser citado para tomarle declaración y respecto del que se ha emitido una orden de detención, tiene derecho a la asistencia letrada. Le surge la duda acerca de si la consecuencia que se deriva de la normativa interna aplicable según la interpretación del Tribunal Constitucional español, consistente en demorar la asistencia letrada hasta que el sospechoso comparezca ante el Juzgado a raíz de la ejecución de una orden de búsqueda y detención nacional, europea o internacional, es compatible con el art. 3.2 Dir. 2013/48 interpretado a la luz del art. 47 CDFUE $^{29}$.

El TJUE responde la cuestión prejudicial declarando la incompatibilidad, con las referidas normas de derecho UE, de la interpretación que efectúa la jurisprudencia nacional, en particular del TC, del art. 24 CE y 118 LECrim, "según la cual, durante la fase de instrucción, el disfrute del derecho a la asistencia de letrado puede demorarse, por razón de la incomparecencia del sospechoso o acusado tras habérsele practicado la citación para comparecer ante un juzgado de instrucción, hasta la ejecución de la orden de detención nacional dictada contra el interesado". Motiva esta decisión en una valora-

29 Según consta en las conclusiones del Abogado General (apdo. 16) y en la STJUE asunto $V W$ (2020) (apdo. 16), el Juzgado de Instrucción n. ${ }^{\circ} 4$ de Badalona funda la pertinencia de su pregunta en que los tribunales españoles, TS y TC, han interpretado ciertas disposiciones nacionales en el sentido de que puede condicionarse el derecho a la asistencia de letrado a la comparecencia personal del investigado. Ello implica que el ejercicio de tal derecho puede ser denegado en los supuestos en que aquel no comparece a la primera citación, dictándose contra el una orden de detención. Debe ponerse de manifiesto que el Juzgado remitente solo alude a los arts. 118 y 527 LECrim, y solo cita la STC 87/1984. Pero no consta ni en las conclusiones ni en la sentencia que en el auto de reenvío se hubiera hecho constar, de un lado, que en el sistema de justicia penal español rige el principio de sujeción del sospechoso al procedimiento que explica, entre otras muchas instituciones y deberes, la rebeldía y el deber de comparecer; y, de otro, que a través de diversas sentencias (cfr. por todas STC 24/2018) el TC ha sentado una doctrina en la que se ha ocupado de detallar en qué circunstancias puede entenderse compatible con el derecho de defensa (arts. 24 CE y 118 LECrim) una decisión judicial que rechaza la personación del investigado o acusado mediante abogado y procurador por haberse aquel sustraído, voluntariamente, a la acción de la Justicia. Según dicha doctrina, resulta necesario, primero, que el condicionamiento judicial del ejercicio del derecho de defensa a la comparecencia personal esté impuesto por una norma legal o se infiera, razonablemente, de las reglas que la disciplinan; y, segundo, que la negativa judicial a la personación del investigado mediante a abogado y procurador tenga un objetivo legítimo y supere el juicio de proporcionalidad, en el que deben ser ponderados diversos factores: hechos punibles imputados, tipo de proceso penal, actos procesales que se tramitan en la concreta fase procesal en la que no se permite ejercer al rebelde el derecho de defensa y efectos jurídicos de esos actos. 
ción conjunta de los objetivos y sistemática de la Dir. 2013/48/UE, así como del tenor literal del su art. $3.2^{\circ}$. Precisa que el disfrute del derecho a la asistencia letrada se genera desde que tenga lugar el primero de los momentos relacionados en el art. 3.2 $2^{\circ}$; que la incomparecencia no es una de las razones por las que puede dejarse de aplicar, temporalmente, tal derecho ya que no está incluida en el catálogo exhaustivo de circunstancias previsto en el art. $3.5^{\circ}$ y $6^{\circ 31}$; y, finalmente, que las exigencias del derecho fundamental a la tutela judicial efectiva consagrado en el art. 47 CDFUE repelen la demora en el ejercicio de aquel derecho por razón de la incomparecencia del sospechoso tras haber sido citado 32 .

\section{ENJUICIAMIENTO EN AUSENCIA DE MENORES ACUSADOS EN EL ORDENAMIENTO JURÍDICO ESPAÑOL}

\subsection{Normativa aplicable}

En España no se ha promulgado un código penal de menores, de modo que los delitos que estos cometen se hallan tipificados en las mismas normas que se aplican a los adultos. Ahora bien, el procedimiento a través del cual se declara la responsabilidad penal de los menores, así como las consecuencias jurídicas que lleva aparejadas sí están regulados en una ley especial: la LO 5/2000.

30 Esos momentos son: “a) antes de que el sospechoso o acusado sea interrogado por la policía u otras fuerzas o cuerpos de seguridad o autoridades judiciales; b) en el momento en que las autoridades de instrucción u otras autoridades competentes realicen una actuación de investigación o de obtención de pruebas -ruedas de reconocimiento, careos o reconstrucciones de hechos-; c) sin demora injustificada tras la privación de libertad; d) con la suficiente antelación antes de que el sospechoso o acusado citado a personarse ante el tribunal competente en materia penal se presente ante dicho tribunal".

31 La asistencia letrada únicamente puede ser demorada en la fase de instrucción y si se da alguna de las circunstancias siguientes: "lejanía geográfica de un sospechoso o acusado" (art. 3.5'), "necesidad urgente de evitar graves consecuencias adversas para la vida, la libertad o la integridad física de una persona" (art. 3.6 a) y "necesidad urgente de una actuación inmediata de las autoridades de instrucción para evitar comprometer de modo grave el proceso penal" (art. 3.6 $\mathrm{b}$ ).

32 En el apdo. 47 de la sentencia no se especifican cuáles son las exigencias del art. 47 CDFUE que prohibirían diferir el ejercicio del derecho a la asistencia letrada en casos de incomparecencia voluntaria del sospechoso. Sí arroja más luz sobre la cuestión el razonamiento del Abogado General en el apdo. 46 de sus conclusiones. En efecto, apoyándose en los considerandos de la Dir. 2013/48 sostiene que el letrado ha de poder "ejercer sin restricciones los aspectos fundamentales de la defensa". Tales aspectos fundamentales comprenden, a su entender, "toda la gama de servicios" asociados a la asistencia letrada puesto que el art. 47 CDFUE, al acotar el contenido esencial del derecho a la asistencia letrada, lo hace en los siguientes términos que son resaltados por el Abogado General: "Toda persona podrá hacerse aconsejar, defender y representar". 
La particular configuración de dicho procedimiento obedece a la especial naturaleza de las medidas que cabe imponer a los menores delincuentes, no siendo únicamente sancionadora sino que, por exigencias del principio del interés superior del menor, ha de ser a la vez educativa. En cualquier caso, la especial consideración de índole procesal que sea dispensada a los menores infractores, de 14 a 18 años, no puede dejar de ser respetuosa con los derechos y garantías fundamentales que con carácter general la CE (1978) reconoce a cualquier persona acusada en un proceso penal, en particular, el derecho a un proceso con todas las garantías y el derecho de defensa (art. 24.2 CE 1978) ${ }^{33}$. Por esta razón, como paso previo a efectuar unas concretas referencias al enjuiciamiento de menores acusados que no han comparecido el día de celebración del juicio, es conveniente hacer una sucinta referencia a la normativa que introdujo en el sistema procesal penal español la posibilidad de enjuiciar en ausencia.

Dicha incorporación tuvo lugar por la LO 7/1988 que, además de instaurar los Juzgados de lo Penal y reformar la LOPJ, modificó diversos preceptos de la LECrim. En lo atinente al derecho de defensa, potenció su vertiente privada al permitir que en el marco del nuevo proceso penal que instaura, el procedimiento abreviado, y cumpliéndose determinados presupuestos y requisitos, el acusado pudiera renunciar a defenderse por sí mismo lo que supuso que, legalmente, podía ser condenado en ausencia ${ }^{34}$. Así, según lo establecido en el art. 793.1 LECrim entonces vigente, la ausencia injustificada del acusado, que hubiera sido citado personalmente o en el domicilio o en la persona que hubiere designado en la primera comparecencia a los efectos de recibir en su nombre las citaciones, no sería causa de suspensión del juicio oral si el juez o tribunal, a solicitud del Ministerio Fiscal o de la parte acusadora y oída la defensa, estimaba que existían elementos suficientes para el enjuiciamiento, y siempre que la pena solicitada no excediera de un año de privación de libertad o, si fuera de distinta naturaleza, superara los seis años.

Como se daba cuenta en la Exposición de motivos de la LO 7/1988, la finalidad que se pretendía alcanzar con la posibilidad de celebrar juicios en ausencia del acusado por delitos no graves era evitar las dilaciones inútiles

33 Así, se reconoce también por los penalistas; cfr. por ejemplo, Pérez Machío (2007, pp. 76-78).

34 La LECrim en su redacción originaria de 1882 no permitía juzgar a reos ausentes. Fueron la L 3/1967 y la LO 10/1980 las que introdujeron en nuestro sistema procesal penal la norma que autorizaba, para el enjuiciamiento de delitos no graves, la celebración del juicio oral cuando la ausencia del acusado era injustificada, siempre que hubiera sido citado personalmente y el juez estimara que existían elementos suficientes para juzgarle. Dichas leyes son los precedentes más próximos de la regulación vigente del enjuiciamiento en ausencia, habiéndose, no obstante, identificado antecedentes de la misma en los efectos jurídicos que, a la incomparecencia del inculpado, se dispusieron en la Partida III. Vid. al respecto, en particular, Garberí Llobregat (1992, pp. 87-94), Gimeno Sendra (1989, pp. 113-117), Gutiérrez Berrinches (2008, pp. 207-209) y Conde-Pumpido Tourón (2003, pp. 631-644). 
derivadas de las suspensiones de los juicios cuando no se presentaba el acusado, que no solo generaban efectos negativos para la recta Administración de Justicia, sino que además perjudicaban a las víctimas. Dicha finalidad se conjugaba con el debido respeto a garantías procesales básicas que se reconocían al acusado, pues, su abogado debía estar presente en el juicio y podía recurrir en anulación la sentencia condenatoria ${ }^{35}$. Con posterioridad a 1988 , el legislador español amplió el ámbito material en el que el enjuiciamiento en ausencia podía tener lugar, pues, con respecto a la pena privativa de libertad la elevó hasta dos años de prisión ${ }^{36}$.

Pues bien, prácticamente desde la entrada en vigor de la LO 5/2000 ha existido una considerable inseguridad jurídica que alcanza no solo a los sujetos del proceso penal, sino también a los justiciables y operadores jurídicos, acerca del ajuste a la legalidad vigente de la celebración del juicio en ausencia del menor acusado. La incertidumbre viene generada por las radicalmente diferentes interpretaciones de su art. 35.1 que dispone:

La audiencia se celebrará con asistencia del Ministerio Fiscal, de las partes personadas, del letrado del menor, de un representante del equipo técnico que haya emitido el informe previsto en el artículo 27 de esta Ley y del propio menor, el cual podrá estar acompañado de sus representantes legales, salvo que el Juez, oídos los citados Ministerio Fiscal, letrado del menor y representante del equipo técnico, acuerde lo contrario. También podrá asistir el representante de la entidad pública de protección o reforma de menores que haya intervenido en las actuaciones de la instrucción, cuando se hubiesen ejecutado medidas cautelares o definitivas impuestas al menor con anterioridad. Igualmente, deberán comparecer la persona o personas a quienes se exija responsabilidad civil; aunque su inasistencia injustificada no será por sí misma causa de suspensión de la audiencia.

\subsection{Inexistencia de uniformidad en la interpretación de la normativa aplicable y pasividad del legislador}

La disparidad en la interpretación y aplicación del precepto transcrito puede ejemplificarse en la emisión de resoluciones judiciales que, partiendo todas ellas de que la LO 5/2000 no contempla expresamente la celebración del juicio en ausencia pero tampoco la prohíbe, resuelven la cuestión de su

35 La Exposición de motivos de la LO 7/1988 finalizaba su argumentación justificativa de la previsión de la celebración del juicio oral en ausencia del acusado subrayando que acataba, especialmente, las orientaciones de la Resolución (75) 11. Aun cuando en la mencionada Exposición de motivos nada se esgrimía sobre el particular, la doctrina ha justificado, con apoyo en la jurisprudencia de su intérprete supremo, que los juicios en ausencia no son contrarios a la CE (1978). En su sentencia 91/2000, FFDD 13 y 14, el Pleno del TC se pronuncia en contra de una proscripción constitucional de la condena in absentia que puede emitirse en determinadas condiciones y atendiendo a intereses públicos dignos de protección. Vid. sobre esta cuestión, Gutiérrez Berrinches (2008, pp. 213-218); y Cedeño Hernán (2010, pp. 276 y 277).

36 Art. 786.1 LECrim establecido por la L 38/2002. 
validez basándose en argumentaciones radicalmente opuestas ${ }^{37}$. Estas argumentaciones pueden ser agrupadas en tres líneas distintas de interpretación de la normativa aplicable.

Según una primera línea interpretativa, del hecho de no prohibir el art. 35.1 LO 5/2000 la celebración de la audiencia en ausencia del menor acusado, cabe inferir que autoriza la aplicación supletoria de lo previsto por la LECrim para el procedimiento abreviado que admite la celebración de la fase de juicio sin que esté presente el acusado, siempre que concurran las circunstancias establecidas en su art. 786.1 LECrim (disposición final primera LO 5/2000). A lo anterior agrega que la celebración del juicio en ausencia se acomoda mejor al interés superior del menor ya que resulta innecesario adoptar medidas cautelares privativas de libertad con el fin de asegurar su presencia en el juicio, evita que se produzcan dilaciones indebidas en la tramitación y se consigue que no se retrase el inicio del tratamiento educativo-socializador del menor infractor. Por otro lado, también se sostiene que al no procederse a la suspensión del juicio se neutraliza la revictimización de los ofendidos y se evita socavar el interés público en la persecución y sanción de los delitos pues resulta factible incorporar al proceso las fuentes de prueba en las que basar los futuros medios de prueba ${ }^{38}$.

Las resoluciones judiciales favorables a la celebración de la audiencia en ausencia del menor acusado tienen importantes singularidades que cabe advertir en cada una de ellas y que de algún modo las individualizan. Así, mientras en algunas se justifica el enjuiciamiento en ausencia en la levedad de los hechos (p. ej., delitos de hurto de uso de ciclomotor) en otras se admite con independencia de la gravedad de los hechos delictivos y de la correspondiente medida que pueda ser acordada, poniendo el acento en que, cuando se trata de una incomparecencia injustificada, la indefensión, en el supuesto de que tenga lugar, se debe a la única y exclusiva voluntad del menor o de sus representantes legales. Por otro lado, la validez de esa forma de enjuiciamiento se suele basar en el previo apercibimiento al menor acerca de los efectos de la designación de un domicilio para notificaciones y en que la medida solicitada no excedía el "plazo legalmente fijado para ello", refiriéndose a dos años de privación de libertad o a seis cuando la medida sea de distinta naturaleza. Las invocaciones a la jurisprudencia del TEDH se hallan presentes también entre las sentencias que no se oponen a la celebración del juicio en ausencia, resaltando que el derecho a estar presente en la audiencia o vista es, en esencia, una facultad del acusado que en el caso de que renuncie al mismo

37 Las diferencias jurisprudenciales en la respuesta a la cuestión de la validez o invalidez de la celebración del juicio en ausencia del acusado menor de edad son expuestas en, Gutiérrez Berrinches (2008, pp. 242-244), Tomé García (2003, pp. 167169), Morenilla Allard (2007, pp. 160 y 161), Fernández-Gallardo Fernández-Gallardo (2015, pp. 243-246), González Pillado (2019, pp. 92-94) y Serrano Masip (2016, pp. 258 y 259 ).

38 Cfr. SAP LE 77/2006, SAP OU 367/2012, SAP L 133/2013, SAP A 278/2013, SAP PO 226/2015, SAP CO 198/2018 y SAP O 82/2020, de 4 de marzo. 
concurriendo las debidas garantías no hay ninguna incompatibilidad con los postulados del derecho a un juicio equitativo.

Una segunda línea hermenéutica es contraria a la celebración de la audiencia en ausencia del menor acusado basándose en que no existe ninguna laguna legal en la LO 5/2000 respecto al enjuiciamiento del menor acusado en ausencia, pues, afirma que el tenor literal del art. 35.1 lo prohíbe. Sin restar trascendencia a la interpretación basada en el sentido propio de las palabras del citado precepto, a nuestro entender, los argumentos decisivos que abogan por la asistencia del menor al juicio en el que se ventila su responsabilidad penal apuntan a la necesidad de velar, simultáneamente, por el pleno ejercicio del derecho de defensa y por la efectividad del interés superior del menor, puesto que, solamente, si este interviene en el proceso, aceptando sus reglas y sometiéndose a ellas, puede alcanzarse la finalidad educativa que se pretende $^{39}$.

De forma similar a como sucede en las resoluciones que no son contrarias a que la audiencia pueda celebrarse a pesar de la incomparecencia del menor, es interesante detenerse en las matizaciones efectuadas por las resoluciones que se oponen a dicha celebración. En alguna de ellas se señala que la indefensión al menor condenado no solo proviene de haberse celebrado la audiencia sin haber estado presente sino porque a lo largo del desarrollo de la instrucción no se le tomó declaración y, en consecuencia, no se le advirtió de forma expresa de que en caso de incomparecencia podría tener lugar el juicio en su ausencia. Asimismo, la circunstancia de que el menor no fuera citado personalmente para asistir a la audiencia, con el apercibimiento de que en caso de incomparecencia podría celebrarse en su ausencia, es alegada como fundamento de la declaración de nulidad de todo lo actuado desde la audiencia. Sin embargo, dándose esa misma circunstancia no se ha estimado procedente declarar la nulidad del juicio celebrado en ausencia cuando el menor acusado ha sido absuelto. Para terminar con las particularidades que se advierten en cada una de las resoluciones examinadas, cabe añadir que se han dictado resoluciones en las que se sostiene que la presencia del menor es preceptiva no solo para los supuestos de enjuiciamiento de delitos graves sino también cuando es acusado por un delito leve.

La tercera línea jurisprudencial que es la que puede acabar siendo aceptada de forma mayoritaria por nuestros tribunales, de modo que sería razonable que el legislador la considerara con detenimiento a los efectos de elevarla a derecho positivo, conjuga los tres criterios siguientes: el relativo a la gravedad de los hechos cometidos, el que circunscribe la nulidad del juicio celebrado en ausencia a los supuestos en los que se haya producido una indefensión constitucionalmente relevante y el atinente al interés superior del

39 Cfr. SAP M 229/2004, SAP CU 50/2005, de 25 de mayo, AAP M 231/2005, SAP BI 47/2005, SAP B 40/2010 y SAP SS 254/2014. 
menor. A los efectos de emitir una opinión sobre la idoneidad de los mismos, es procedente analizar cuál puede ser su alcance ${ }^{40}$.

Antes de la supresión de las faltas por la LO 1/2015 hubo un cierto consenso jurisprudencial en aplicar al enjuiciamiento de menores el art. 971 LECrim que permitía la celebración de los juicios de faltas sin que estuviera presente el acusado. En apoyo de esta posición, se advertía que la levedad de la conducta prevista por la ley penal habría supuesto que la adopción de medidas restrictivas del derecho a la libertad del menor, con el fin de lograr coactivamente su presencia en el juicio, conllevaría la infracción del principio de proporcionalidad ${ }^{41}$. Este argumento se ha mantenido tras la reforma en 2015 del CP y de la LECrim, poniendo de relieve que si bien cuando se trata del enjuiciamiento de hechos constitutivos de delitos graves y menos graves cabe entender que el art. 35 LO 5/2000 exige la presencia del menor en la audiencia, sin que resulte de aplicación supletoria la LECrim, en cambio no es razonable imponerla cuando los hechos que se enjuician son constitutivos de un delito leve. Tampoco han variado las razones en las que se basa, pues, de una parte, se reafirma en que sería desproporcionada la adopción de una medida cautelar privativa de libertad en orden a asegurar la presencia del menor en el juicio y, de otra, en que sería contrario al interés público dejar a merced de la voluntad del menor la celebración del juicio ${ }^{42}$.

El segundo criterio se asienta en la premisa de que la ausencia del menor no comporta por sí misma y de manera ineludible la nulidad del juicio. Esta consecuencia solo podrá decretarse si se ha producido una indefensión constitucionalmente relevante que se manifiesta en la privación de las razonables expectativas de intervenir en el proceso, pero siempre que no sea el resultado de la conducta procesal voluntaria del menor. Por tanto, si la citación se ha efectuado de conformidad con las formalidades legales, quedando constancia de su efectiva recepción por el menor y de que ha sido informado con claridad acerca de la posibilidad de ser juzgado cuando su incomparecencia sea injustificada pero también cuando responda a ciertas razones ${ }^{43}$; si además,

${ }^{40}$ Los criterios referidos pueden extraerse de la ratio decidendi de SAP C 45/2016, SAP BI 28/2018, SAP V 377/2018 y SAP M 56/2019.

41 Cfr. SSAP M 229/2004 y 52/2014.

42 A la gravedad de la conducta se refirió la Circular 1/2000 (VIII.1), de 18 de diciembre, de la FGE precisando que la propia realidad de los hechos cometidos por el menor requería que se arbitrara, con carácter"absolutamente excepcional", la posibilidad del enjuiciamiento en su ausencia. Este criterio, que fue paulatinamente aplicado por las Fiscalías, como se recoge en la Memoria de la FGE de 2006, se consolida en la Circular 1/2007 (IX.1), de 26 de noviembre, de la FGE. Ello ha comportado que Juzgados de Menores y Fiscalías hayan acordado celebrar las audiencias pese a la ausencia del menor acusado, siempre y cuando la medida solicitada sea inferior a dos años de privación de libertad (cfr. memorias de la FGE de 2008, de 2017 y 2019).

${ }^{43}$ Entre las causas que revelan una ausencia justificada del menor en la audiencia, pero que no dan lugar a la suspensión de la misma sino a su celebración, cabe destacar la residencia del menor en un lugar geográficamente distante de la sede del Juzgado de Menores que tramita el asunto, así como, la voluntad del menor de no 
el menor ha gozado de asistencia letrada durante la celebración del juicio y, por último, si está prevista por ley la facultad de incoar un posterior juicio rescisorio de la condena penal en ausencia, el déficit del derecho de defensa derivado de no poder llevar a cabo la autodefensa y de no ejercer el derecho a la última palabra no tiene la trascendencia constitucional necesaria para provocar la nulidad del juicio ${ }^{44}$.

Finalmente, el tercer criterio es el principio del interés superior del menor que es invocado por la gran mayoría de resoluciones judiciales que se pronuncian sobre la validez del juicio celebrado en ausencia del menor y cuya complejidad es notoria, como se constata a raíz de atribuirle postulados que se contradicen entre sí. En efecto, la presencia preceptiva del menor en el juicio se fundamenta en la dimensión educativa de aquel principio, pues permite transmitir el porqué y el cómo de la respuesta de la norma penal frente a la perpetración de conductas delictivas, estimular el reconocimiento de la víctima y fomentar la aceptación del daño causado. Sin embargo, también se argumenta que el enjuiciamiento en ausencia, siempre que el menor, haya sido oído y entrevistado durante la tramitación del expediente por los miembros del equipo técnico con la finalidad de evaluar sus circunstancias personales, familiares y sociales del menor, tiene asimismo una acusada faceta educativa pues, de un lado, pone de manifiesto al menor que la tramitación del proceso penal no depende de su voluntad y, de otro, favorece el inicio en un período de tiempo más corto del programa pedagógico diseñado en la medida impuesta ${ }^{45}$.

Por lo que se refiere a la segunda instancia, la celebración de la vista en ausencia del menor acusado debería estar expresamente regulada por la LO 5/2000 y adecuarse a los tres criterios expuestos. Como es sabido, la L 41/2015 modificó el recurso de apelación contra sentencias dictadas por los Juzgados de lo Penal y los Juzgados Centrales de lo Penal en el procedimiento abreviado. El sistema que instaura, y extiende al recurso de apelación contra sentencias dictadas por las Audiencias Provinciales y la Sala de lo Penal de la Audiencia Nacional, se caracteriza por no otorgar las mismas posibilidades

estar presente en el propio juicio. La eficacia de esta última se condiciona, de una parte, a que haya estado precedida de asesoramiento letrado y, de otra, a la emisión del consentimiento de sus representantes legales cuando el menor tenga una edad comprendida entre 14 y 15 años. Así se configura la ausencia justificada, que legitima la celebración de la audiencia sin que esté presente el menor acusado, en la SAP M $124 / 2020$.

${ }^{44} \mathrm{La}$ doctrina de la indefensión constitucionalmente relevante fue aplicada por el ATC 148/1999 en el que se declaró que no fueron vulnerados los derechos de defensa y a ser oídos de tres menores de edad juzgados en ausencia a los que se imputaba un delito de daños. De conformidad con dicha resolución, para que tenga lugar aquella clase de indefensión han de concurrir dos extremos, primero, ha de tener un carácter material, es decir, ha de causar un real y efectivo menoscabo del derecho de defensa y, segundo, ha de ser atribuible al órgano jurisdiccional.

45 Cfr. Circular 1/2007 FGE (IX.1). 
de impugnación a acusados y acusaciones (art. 790.2 LECrim), por limitar la potestad jurisdiccional del tribunal de segunda instancia (art. 792.2 LECrim) al menos cuando son las acusaciones quienes interponen el recurso de apelación y por mantener la índole facultativa de la celebración de la vista ante dicho tribunal (art. 791 LECrim) ${ }^{46}$. Pero ni la Ley citada ni la LO 13/2015 reformaron la LO 5/2000 en lo relativo al recurso de apelación contra las sentencias dictadas por los Juzgados de Menores.

Uno de los preceptos clave de la segunda instancia en el proceso penal de menores es el art. 41.1 LO 5/2000 según el cual:

Contra la sentencia dictada por el Juez de Menores en el procedimiento regulado en esta Ley cabe recurso de apelación ante la correspondiente Audiencia Provincial, que se interpondrá ante el Juez que dictó aquella en el plazo de cinco días a contar desde su notificación, y se resolverá previa celebración de vista pública, salvo que en interés de la persona imputada o de la víctima, el Juez acuerde que se celebre a puerta cerrada. A la vista deberán asistir las partes y, si el Tribunal lo considera oportuno, el representante del equipo técnico y le representante de la entidad pública de protección o reforma de menores que haya intervenido en el caso concreto. El recurrente podrá solicitar del Tribunal la práctica de la prueba que, propuesta y admitida en la instancia no se hubiera celebrado, conforme a las reglas de la Ley de Enjuiciamiento Criminal.

Este precepto prevé, de forma específica, normas sobre: competencia funcional, plazo para interponer el recurso, celebración preceptiva de la vista a la que deben asistir las partes y medios de prueba que pueden ser practicados. Ello supone que, de conformidad con la disposición final primera LO 5/2000, a los restantes extremos que completan la disciplina del recurso de apelación contra sentencias dictadas en el proceso penal de menores no previstos en la citada LO, por ejemplo, los motivos en los que se basa el recurso, les deben ser aplicados los arts. 790 a 792 LECrim $^{47}$. De ahí que, de un lado, acusado y acusaciones tengan distintas posibilidades de impugnación de la sentencia de primera instancia y, de otro, el tribunal de segunda instancia tenga limitada su potestad jurisdiccional al no poder revocar la sentencia absolutoria de primera instancia y dictar otra en la que exprese su propia valoración de la prueba.

Ambas particularidades se manifiestan cuando el motivo en el que ha de fundarse el recurso de apelación es el error en la valoración de la prueba ya que en el supuesto de que sean las acusaciones las que lo aleguen habrán de justificar la insuficiencia o la falta de racionalidad en la motivación fáctica, el apartamiento manifiesto de las máximas de la experiencia o la omisión de todo razonamiento sobre alguna o alguna de las pruebas practicadas que

46 Vid. en especial, Bellido Penadés (2015), González-Cuéllar Serrano (2015, pp. 533-538), Muerza Esparza (2015, pp. 79-89), Etxeberría Guridi (2019, pp. 482487), Cortés Domínguez (2019, pp. 621-628) y Armenta Deu (2019, pp. 350 y 351).

47 Esta es la conclusión a la que llega la FGE en la Circular 1/2018 (apdo. 8), de 1 de junio de 2018, sobre algunas cuestiones que suscita la nueva regulación de la segunda instancia en materia penal. 
pudieran tener relevancia o cuya nulidad haya sido improcedentemente declarada. Y, si el motivo es estimado por el tribunal de segunda instancia, no podrá condenar al apelado que resultó absuelto en primera instancia ni agravar su condena, sino que se limitará a anular la sentencia y a devolver las actuaciones al tribunal de primera instancia. En estos casos, en principio, no habría necesidad de examinar si la ausencia del apelado en la vista es compatible con la jurisprudencia del TEDH puesto que el tribunal de segunda instancia no emitirá una decisión acerca de la culpabilidad o inocencia de aquel.

Por el contrario, aquel examen sí es preciso cuando ha sido impugnada una sentencia condenatoria. Al respecto, debe recordarse que tanto el TS como el TC entienden que la esfera de la intervención del tribunal de apelación no es la misma cuando ha de resolver un recurso contra una sentencia condenatoria que cuando ha de hacerlo respecto de una absolutoria, pese a basarse ambos recursos en el error en la apreciación de las pruebas. En el primer supuesto, su intervención radica en examinar "la legitimación de la decisión adoptada en la instancia" y consiste en "verificar la solidez y razonabilidad de las conclusiones alcanzadas, confirmándolas o rechazándolas" 48 . Esta concepción es compartida por el TC, pues, afirma que el análisis por parte del tribunal de segunda instancia de la actividad probatoria de primera se centra en poder decidir si hubo prueba de cargo suficiente para enervar la presunción de inocencia, si esa prueba de cargo fue constitucionalmente obtenida y legalmente practicada, si fue valorada racionalmente y, en último término, si los motivos de la valoración fueron expuestos según los estándares de suficiencia ${ }^{49}$. Lo más trascendente de estos argumentos es que el control por el tribunal ad quem de la suficiencia, licitud y validez de la prueba de cargo, así como de la motivación racional de sus resultados, que puede dar lugar a la absolución o a la reducción de la gravedad de la pena impuesta y, por consiguiente, a la sustitución de la valoración de la prueba efectuada por el tribunal a quo, no requiere la inmediación. La razón que permite eludir la aplicación de dicho principio es que los hechos declarados probados en primera instancia no van a ser modificados.

No obstante, al final de todo el anterior razonamiento surge la duda relativa a si en un recurso de apelación contra sentencia condenatoria interpuesto por la parte acusada cabe invocar algún extremo distinto, dentro del ámbito del error en la valoración probatoria, al dirigido a poner de manifiesto que en primera instancia no se ha conseguido enervar la presunción de inocencia. En otras palabras, la cuestión estriba en si la parte acusada puede invocar algún error en la valoración de la prueba sobre el cual el tribunal de segunda instancia solo puede pronunciarse si se cumple con la inmediación. Pues bien, entendemos que sí, ya que el motivo de impugnación de la sentencia dictada en primera instancia puede estar fundado en la inaplicación del principio in dubio pro reo que se constata, por ejemplo, en las dudas

\footnotetext{
48 STS 945/2013, FD 6.

49 Cfr. STC 120/2009.
} 
expresadas por el tribunal a quo acerca de la concurrencia de los elementos objetivos del tipo a raíz de una posible coartada favorable al condenado suministrada por las declaraciones de un testigo ${ }^{50}$. En estos supuestos, en los que el tribunal de segunda instancia deberá revisar el juicio de hecho contenido en la sentencia de primera instancia, debería celebrarse vista con la presencia del menor condenado; si no compareciera, la vista se tramitaría cuando su ausencia fuera compatible con la jurisprudencia del TEDH.

Tras exponer el tema relativo al enjuiciamiento en ausencia de menores acusados por nuestros tribunales de justicia, la pregunta que surge de inmediato es cómo reacciona ante esa realidad forense el legislador español. Pues, bien, de conformidad con los datos que constan en EUR-Lex, España ha comunicado a la Comisión que ya ha transpuesto la Dir. 2016/800 ${ }^{51}$. Pero de la relación de diez normas que, entre esos datos, figura con el fin de demostrar que se ha efectuado la transposición aludida, solamente la L 23/2014 ha sido reformada, con vistas a adaptarla a la Dir. 2016/800, por la L 3/2018 en cuyo Preámbulo (IV), se lee que el motivo de la modificación es adecuar la L 23/2014 a los derechos procesales de los menores sospechosos o acusados reconocidos en esa Directiva. Ahora bien, del texto legal solo se modifica un precepto ubicado en sede de ejecución de la orden de detención europea, el art. 50, que prevé para los menores de edad reclamados un plazo máximo reducido para pasar a disposición judicial del Juzgado Central de Menores que es el de 24 horas desde su detención. Respecto de la LO 5/2000 ninguna reforma se ha producido desde la operada por la LO 8/2012.

La situación de inseguridad jurídica y la desigualdad de trato a los menores en conflicto con la Administración de Justicia que, inevitablemente, ha de derivarse de los distintos enfoques que la jurisprudencia da a la posibilidad de que se celebre la audiencia ante la incomparecencia del menor acusado, y que ha quedado puesta de manifiesto con el análisis llevado a cabo en este epígrafe, convierte en difícilmente explicable que no se haya presentado ninguna iniciativa legislativa en la que se proponga una modificación del art. 35.1 LO 5/2000 en la que se dispusiera con toda claridad si la audiencia puede celebrarse en ausencia del menor ${ }^{52}$.

${ }^{50}$ La singularidad del principio in dubio pro reo respecto de la presunción de inocencia, así como sus diferentes manifestaciones son explicadas, recogiendo la jurisprudencia del TC y del TS por Fernández López (2005, pp. 161-176).

51 Web consultada por última vez el 1 de septiembre de 2020. Asimismo, en el documento Fundamental Rights Report 2019, elaborado por la Agencia de los derechos fundamentales de la UE (FRA), p. 188, consta que España ha notificado a la Comisión la completa transposición de la Dir. 2016/800.

52 La única iniciativa legislativa que se está tramitando en la actualidad que reforma la LO 5/2000 es el Proyecto de Ley Orgánica de protección integral a la infancia y la adolescencia frente a la violencia (DOCG, Congreso de los Diputados, Serie A, n. ${ }^{\circ} 22-1$, de 19 de junio de 2020). Ahora bien, solo se propone la modificación del art. 4 LO 5/2000 con el fin de profundizar en los derechos a la información y a la participación en el procedimiento que corresponden a las víctimas y personas perjudicadas por las infracciones cometidas por los menores de edad (DF 9). 


\section{IDENTIFICACIÓN DEL LÍMITE IMPUESTO POR LA CLÁUSULA DE "NO REGRESIÓN", PREVISTA EN LA DIRECTIVA (UE) 2016/800, A UNA FUTURA INCORPORACIÓN DEL ENJUICIAMIENTO EN AUSENCIA DE MENORES AL SISTEMA PROCESAL PENAL ESPAÑOL}

\subsection{Planteamiento del problema: cláusula de "no regresión" de la Directiva (UE) 2016/800 como obstáculo a la iniciativa legislativa nacional}

El objeto de este estudio comporta que una de las reformas de la LO $5 / 2000$, que estimamos debería acometerse se centre en la celebración del juicio en ausencia, aun cuando también debería abarcar un momento procesal anterior, esto es la tramitación del expediente, puesto que de las garantías que en el se salvaguarden dependerá, de conformidad con el Derecho español y el de la UE, la legitimidad de aquel juicio.

Tal reforma debería consistir en prever de forma expresa la posibilidad de enjuiciar en ausencia al menor acusado cuando concurrieran las condiciones establecidas de una parte, como estándares mínimos por el Derecho de la UE y el CEDH y, de otra, por la LECrim que ya han sido expuestas en epígrafes anteriores.

A través de la modificación legislativa en el sentido propuesto, podría hallarse una razonable solución jurídica a las dudas que, en el marco legislativo actual, pueden planteárseles a los Juzgados de Menores referentes a: si de conformidad con lo previsto en el art. 16.2 Dir. 2016/800 y arts. 8 y 9 Dir. 2016/343 un menor acusado puede ser juzgado pese a no haber comparecido con independencia de la gravedad del delito que se le impute; o únicamente podría serlo concurriendo las condiciones previstas en los preceptos de las anteriores Directivas y, además, en el art. 786.1 LECrim. Pero incluso cabe estimar que la entrada en vigor estos dos instrumentos normativos UE y su transposición poco pueden contribuir a resolver el estado de incertidumbre descrita ni a superar la discriminación entre menores acusados ocasionada por el lugar donde han perpetrado el delito. Y ello en virtud de la eficacia que se estime han de tener las cláusulas de "no regresión" contempladas en cada una de las dos Directivas mencionadas.

La relevancia del tema de la eficacia de la cláusula de "no regresión" del art. 23 Dir. 2016/800, cuando se acomete la adaptación del Derecho español a la misma, ha sido puesta de manifiesto por la doctrina al observar que"no será factible aprovechar su transposición para introducir en la ley la posibilidad de juicio en ausencia" ${ }^{53}$. Sin embargo, teniendo en cuenta las divergencias insuperables en la jurisprudencia española sobre la celebración del

\footnotetext{
53 Arangüena Fanego (2019, p. 30).
} 
juicio en ausencia del menor no resulta improcedente incidir en el análisis de los efectos de dicha cláusula, no ya en la labor de trasponer la Directiva al ordenamiento jurídico español, sino particularmente en la función que compete al legislador español de solventar, a través de modificaciones legales, las cuestiones que emergen de la aplicación de las normas y que se traducen, como es el caso del art. 35 LO 5/2000, en vulneraciones del principio de igualdad, así como en la provocación de inseguridad jurídica, y cuyas principales responsables son las deficiencias constatadas en aquellas por no cumplir con el nivel de calidad exigible o no integrarse de forma armónica en el sistema jurídico al que pertenecen.

Como ha sido señalado en líneas superiores, la redacción del art. 16.2 Dir. 2016/800 demuestra que las instituciones de la UE conocen los sistemas procesales penales de los Estados miembros y saben que algunos de ellos contemplan la posibilidad de juzgar a los menores en ausencia. Ante esta constatación, solamente les impone un deber que es el de velar porque esos menores tengan derecho bien a un nuevo juicio bien a otro tipo de recurso judicial "con arreglo a las condiciones establecidas en la Directiva (UE) 2016/343".

Esta remisión a unos preceptos concretos de la Dir. 2016/343 comporta que el legislador nacional, cuando se disponga a transponer la Dir. 2016/800 deba, en primer lugar, tener en cuenta la cláusula de "no regresión" incluida en esta última Directiva ${ }^{54} \mathrm{y}$, en segundo lugar, una vez haya estimado que dicha cláusula no le impide legislar sobre el enjuiciamiento en ausencia, ha de observar la cláusula de "no regresión" de la Dir. 2016/343 ${ }^{55}$, de modo que deberá comparar los arts. 8 y 9 que tratan de las garantías del derecho a estar en el propio juicio con la regulación nacional ya existente al respecto. En este último punto, a pesar de que las garantías procesales del derecho a estar presente en el juicio previstas en las Directivas europeas no difieren según se trate de mayores o menores de 18 años, el legislador nacional habrá de averiguar si han sido aprobadas normas internacionales o internas específicas para menores que prevean un grado de protección más elevado.

En suma, la tarea que es ineludible llevar a cabo va a consistir en dilucidar hasta qué punto las cláusulas de "no regresión" examinadas restringen la

54 La cláusula de no regresión de la Dir. 2016/800 que prevé el art. 23 está redactada en los términos siguientes: "Ninguna disposición de la presente Directiva se interpretará en el sentido de que introduce limitaciones o excepciones a los derechos o garantías procesales reconocidos por la Carta, el CEDH u otras disposiciones aplicables de Derecho Internacional, en particular, la Convención de las Naciones Unidas sobre los Derechos del Niño, o a la normativa de cualquier Estado miembro que garantice un nivel de protección superior".

55 La cláusula de no regresión de la Dir. 2016/343 se halla regulada en su art. 13 en los términos siguientes: "Ninguna disposición de la presente Directiva se interpretará en el sentido de limitar o derogar los derechos o las garantías procesales que estén reconocidos al amparo de la Carta, del CEDH y de otras disposiciones pertinente del Derecho internacional o del Derecho de cualquier Estado miembro que garantice un nivel superior de protección más elevado". 
autonomía legislativa nacional llegando incluso a prohibir u obstaculizar la reforma de la LO 5/2000 para prever la posibilidad de enjuiciar y, por tanto, condenar al menor acusado que no comparece en la audiencia.

\subsection{Una posible respuesta: análisis de la naturaleza y finalidad de la cláusula de"no regresión" de la Directiva (UE) 2016/800}

Planteado el problema en esos términos, la proposición de una posible respuesta al mismo requiere, a nuestro entender, que el primer paso estribe en determinar la naturaleza y la finalidad de las cláusulas de "no regresión". Una vez clarificados estos extremos, y teniendo en cuenta el estado de la situación en la práctica forense española, se podrá concluir si se ajusta a la Dir. 2016/800 la modificación de la LO 5/2000 con vistas a permitir la celebración de la audiencia en ausencia del menor acusado. En el caso de que se estimara que dicha modificación no es contraria a la cláusula de "no regresión", o que esta no es aplicable, habrá de efectuarse una propuesta acerca de las condiciones que deberán ser observadas por la normativa que regule el enjuiciamiento en ausencia de menores acusados.

Una vía que puede contribuir a fijar la naturaleza de la cláusula de "no regresión" de la Dir. 2016/800 es confrontarla, si bien de forma concisa, con las que constituyen su referente más próximo. Estas son las que se insertan en el CEDH y en la CDFUE que a su vez tienen un contenido muy similar a las cláusulas de "no regresión" que forman parte de los convenios internacionales sobre reconocimiento y protección de derechos fundamentales. En ellas se suele fijar el nivel de protección de los derechos que constituyen su objeto respecto del otorgado en otros convenios internacionales, así como en los respectivos derechos nacionales de los Estados parte, por lo que también reciben el nombre de cláusulas de "maximización", de "protección máxima" o de "no empeoramiento".

El CEDH la prevé en su art. 53 con el fin de advertir que los derechos humanos y las libertades fundamentales que consagra no deben ser utilizados como pretexto para limitar o imponer restricciones a los que son sancionados por los Estados parte o por otros tratados internacionales ${ }^{56}$. Cabe, pues, entender que a través de ella se ha querido subrayar, de un lado, la naturaleza subsidiaria de la protección que proporciona el CEDH y, de otro, la función que ha de realizar la cláusula que no es otra que la propia de una regla de conflicto; es decir, si respecto de un mismo derecho o libertad las interpretacio-

56 El art. 53 CEDH, cuyo título es "Protección de los derechos humanos reconocidos", establece lo siguiente: "Ninguna de las disposiciones del presente Convenio se interpretará en el sentido de limitar o perjudicar aquellos derechos humanos y libertades fundamentales que podrían ser reconocidos conforme a las leyes de cualquier Alta Parte Contratante o en cualquier otro Convenio en el que esta sea parte". 
nes llevadas a cabo por el TEDH y por los tribunales nacionales difieren, solo debe darse preferencia a la primera si los protege con mayor intensidad ${ }^{57}$. Pese a la importancia que en el sistema del CEDH se concedió en un principio a la cláusula de "no regresión", la aplicación que de ella ha realizado el TEDH ha sido excepcional ${ }^{58}$. Uno de los motivos de no haber desplegado el potencial que de ella se esperaba radica en la creación por el TEDH de la doctrina del margen de apreciación nacional, más acorde con la subsidiariedad que la cláusula de "maximización", y que se ha convertido en el mecanismo principal al que acude el Tribunal de Estrasburgo en orden a poder conseguir un equilibrio entre la natural diversidad de sistemas de garantías existentes en los Estados parte del CEDH y su posición como tribunal supranacional ${ }^{59}$.

En la CDFUE también se incluye un precepto, el art. 53, que contiene una cláusula de "no regresión" de derechos fundamentales ${ }^{60}$. Su objetivo no es otro que el de impedir que se interprete y aplique la CDFUE para disminuir el nivel de protección que el concreto derecho tiene en su respectivo ordenamiento jurídico bien sea el de la UE, el internacional o el de los Estados miembros. No pretende, por tanto, instaurar una jerarquía de sistemas jurídicos basada en el nivel más alto de protección concedido por cada uno de ellos al derecho o la libertad de que se trate ya que ello podría debilitar los principios de primacía, unidad y eficacia del Derecho de la UE, al ser susceptible de ser utilizada a modo de instrumento de resolución de conflictos de derechos

57 Vid., entre otros, Martín y Pérez de Nanclares (2008, pp. 853-856) y Van de Heyning (2011, pp. 71-82).

58 Como han subrayado los autores que han profundizado sobre el tema, la resolución de las demandas formuladas aplicando el art. $53 \mathrm{CEDH}$ ha tenido lugar en los asuntos Handyside c. Reino Unido (1976), Ekbatani c. Suecia (1988), Open Door y Dublin Well Woman c. Irlanda (1992) y Burghartz c. Suiza (1994). Cfr. Martín y Pérez de Nanclares (2008, p. 856).

59 En síntesis y siguiendo a García Roca, puede decirse que la doctrina del margen de apreciación nacional comporta, para los Estados parte, una cierta discrecionalidad respecto a la aplicación y cumplimiento de las obligaciones impuestas por el CEDH y, para el TEDH, opera a modo de regla de contención, autolimitación o deferencia cuando la solución adoptada por el Estado parte demandado tiene una "razonable apariencia de buen derecho". Con base en dicha regla, el TEDH no ha de sustituir las apreciaciones de las autoridades nacionales respecto a la prueba de los hechos, la interpretación de la legalidad ordinaria y la libre configuración de los derechos por los ordenamientos nacionales siempre que respeten su contenido esencial. Este último extremo es crucial en la aplicación del margen de apreciación nacional, pues, su amplitud varía en función de la naturaleza del derecho o la libertad implicada. Vid. García Roca (2009, pp. 27-39) y Van de Heyning (2012, pp. 151-159).

${ }^{60} \mathrm{El}$ art. 53 CDFUE, que lleva por título "Nivel de protección", prevé que "ninguna de las disposiciones de la presente Carta podrá interpretarse como limitativa o lesiva de los derechos humanos y libertades fundamentales reconocidos, en su respectivo ámbito de aplicación, por el Derecho de la Unión, el Derecho internacional y los convenios internacionales de los que son parte la Unión o todos los Estados miembros, y en particular el Convenio Europeo para la Protección de los Derechos Humanos y de las Libertades Fundamentales, así como por las constituciones de los Estados miembros". 
fundamentales, sino mantener el statu quo en la protección de aquellos ${ }^{61}$. Siendo tal fin de notoria importancia, no debe desterrarse el dinamismo que la CDFUE, derivado de ser un texto constitucional con autonomía, ha de imprimir a la evolución de la protección de los derechos fundamentales incrementando los estándares aplicables. Ahora bien, también debe repararse en que la cláusula de "no regresión" no establece niveles de protección determinados, simplemente evita que se produzca un menoscabo en materia de derechos fundamentales en el seno de la UE ${ }^{62}$.

Pese a la incorporación de la cláusula de "no regresión" en el art. 53, esto es, en el título de la CDFUE donde se ubican las disposiciones generales que diseñan un régimen jurídico común a todos los derechos fundamentales en cuanto a su interpretación y aplicación, por tanto aplicables también al derecho a la tutela judicial efectiva y a un proceso equitativo (art. 47 CDFUE) y a la defensa (art. 48 CDFUE), las Dirs. 2016/343 y 2016/800, al igual que las restantes Directivas ya aprobadas sobre derechos y garantías procesales de sospechosos y acusados en procesos penales, incluyen en sus textos articulados cláusulas de "no regresión". Seguramente, el factor determinante de tal inclusión habrá sido la materia sobre la que versan. En cualquier caso, su naturaleza jurídica, dado que pertenecen al ordenamiento jurídico UE, se ha de aproximar más a la de la cláusula prevista en la CDFUE que a la contemplada en el CEDH. Sin embargo, el hecho de que coincidan en el propósito de evitar que se produzca una rebaja en los estándares de protección de derechos fundamentales en la $\mathrm{UE}^{63}$, no ha de impedir observar las particularidades de las cláusulas de "no regresión" cuando se insertan en instrumentos normativos de derecho derivado, como son las Directivas que han de ser transpuestas a los ordenamientos jurídicos nacionales por el respectivo poder legislativo.

${ }^{61}$ Este es el sentido otorgado por la Explicación del Praesidium de la Convención al art. 53 pues en ella se aclara que pretende "mantener el nivel de protección que ofrecen actualmente en sus respectivos ámbitos de aplicación el Derecho de la Unión, el Derecho de los Estados miembros y el Derecho Internacional"; asimismo, señala que la mención expresa al CEDH se debe a su importancia (DOUE, C 303, 14.12.2007, p. 35). Vid. los análisis del art. 53 CDFUE realizados por Mangas Martín (2005, pp. 218-222), Martín y Pérez de Nanclares (2008, pp. 856-868, Monereo Pérez (2012, pp. 1399-1406) y Arold Lorenz, Groussot y Petursson (2013, pp. 209-215).

${ }^{62}$ A los niveles de protección se refiere, más propiamente, el art. 52 CDFUE. La conexión entre los arts. 51, 52 y 53 CDFUE fue explicada en la STJUE Melloni (2013). Dicha resolución vino a contradecir las interpretaciones del art. 53 CDFUE según las cuales dicho precepto contemplaba una norma de conflicto que conllevaba la aplicación de la norma que confería mayor protección a un derecho fundamental y operaba desplazando el menor estándar de protección reconocido al mismo derecho en el ámbito de la UE que era sustituido por el de mayor protección formulado en otro ordenamiento jurídico.

63 Evitar que las normas mínimas sobre derechos y garantías procesales a sospechosos y acusados en procesos penales "supongan un nivel de protección a la baja en el espacio judicial comunitario", es la función que la doctrina atribuye a las cláusulas de "no regresión" presentes en las Directivas sobre la materia. Vid. Jimeno Bulnes (2011a, p. 122). 
A diferencia de otros ámbitos materiales en los que se ha atribuido competencia a la UE, como es el de las políticas sociales, en el de la cooperación judicial en materia penal no se han planteado, hasta el momento, cuestiones prejudiciales que hayan forzado al TJUE a interpretar las cláusulas de "no regresión" desvelando su naturaleza y finalidad. Sin embargo, algunos de los criterios que han servido al Tribunal de Luxemburgo para aclarar los mencionados extremos en las cláusulas de "no regresión", incluidas en Directivas sobre derechos de los trabajadores, pueden ser, a nuestro juicio, aplicables a las previstas en las Dirs. 2013/343 y 2016/800 ${ }^{64}$. La razón se halla en que tanto el campo de los derechos sociales como en el de la cooperación judicial penal, las Directivas son actos legislativos a través de los cuales se suele articular la distribución de las competencias compartidas, o mejor concurrentes, entre la UE y los Estados miembros. Teniendo presente que el sentido que se dé a las cláusulas de "no regresión" insertas en las Directivas puede llegar a ser un factor que coadyuve a que la UE desplace la competencia nacional ocupando su terreno ${ }^{65}$, es apropiado examinar la aplicación en la cooperación judicial en materia penal de tres criterios cuya transversalidad es innegable y que son susceptibles de frenar la tendencia expansiva de la actividad legislativa UE que, por otro lado, alienta el art. 2.2 TFUE.

El primer criterio al que puede acudirse con vistas a delimitar la naturaleza y finalidad de las cláusulas de "no regresión" de las Dirs. 2016/343 y 2016/800 es el del alcance de la competencia que, a través de las mismas, puede llegar a desarrollar la UE. En teoría, las normas mínimas no son reglas exhaustivas pues no prevén todas las manifestaciones que pueden derivarse de los derechos y garantías procesales objeto de regulación. Por otro lado, la función que les otorga el art. 82 TFUE es la de agilizar la cooperación judicial en materia penal. Con ello se quiere destacar que la finalidad funcional constituye el elemento que ha de limitar el ejercicio de la competencia de la UE.

No obstante, el criterio de la competencia de los Estados miembros, en materia de derechos y garantías procesales de sospechosos y acusados en procesos penales, no contribuye a resolver las dudas que sobre la eficacia de las cláusulas de "no regresión" se plantean. El motivo se halla en la decidida ampliación por parte del TJUE de lo que, en rigor, constituye el ámbito material de aplicación de las Directivas que establecen normas mínimas sobre aquellos derechos y garantías procesales.

Como es sabido, la delimitación de las competencias de la UE se rige por el principio de atribución, en cuya virtud esta ha de actuar dentro de los límites de las competencias que le atribuyen los Estados miembros en los Trata-

${ }^{64}$ Nos referimos a las Dirs. 1999/70 y 2000/78. El sentido de las cláusulas de "no regresión" insertadas en estas últimas Directivas han sido interpretadas por el TJUE, principalmente, en sus sentencias Mangold (2005), Angelidaki (2009) y Sorge (2010). Dos análisis doctrinales de las anteriores resoluciones han sido efectuados por Vigneau (2006, pp. 521-524) y Peers (2010, pp. 436-443).

65 Cfr. Mangas Martín (2014, pp. 75-77). 
dos para lograr los objetivos en ellos fijados (art. 5.1 y 2 TUE). Tales límites y objetivos adquieren particular relieve cuando la UE ha de ejercer sus atribuciones respecto de las competencias compartidas con los Estados miembros. Una de esta clase de competencias es la relativa al espacio de libertad, seguridad y justicia [art. 4.2.j) TFUE] en el que la UE adopta medidas tendentes a promover la cooperación judicial en materia penal que, además de basarse en el principio de reconocimiento mutuo de sentencias y resoluciones judiciales, incluye la aproximación de legislaciones (art. 82.1 TFUE). Dicha aproximación está sujeta, de un lado, a la observancia de un límite de índole material ya que ha de proyectarse sobre determinados ámbitos, siendo uno de ellos los "derechos de las personas durante el procedimiento penal" y, de otro, al cumplimiento de un objetivo de "facilitar el reconocimiento mutuo de las sentencias y resoluciones judiciales y la cooperación policial y judicial en asuntos penales con dimensión transfronteriza" (art. 82.2 TFUE).

Pues bien, a las normas mínimas de las Directivas sobre derechos y garantías procesales a sospechosos y acusados en procesos penales, se les está concediendo una fuerza expansiva por la vía de dotarles de eficacia más allá del objetivo fijado en el art. 82.2 TFUE. Aunque parte de la doctrina se muestra favorable a tal tendencia ${ }^{66}$, es el TJUE el responsable de que aquellas normas sobrepasen el marco de la cooperación transfronteriza gracias a una interpretación amplia del art. 82.2 TFUE. Frente al argumento que rechaza la competencia interpretativa del TJUE cuando los asuntos concretos no tienen ningún elemento transfronterizo, el TJUE ha afirmado, hasta el momento, que las Dirs. 2012/13 y 2013/48/UE se asientan en la premisa de que el principio de reconocimiento mutuo exige que las resoluciones de las autoridades judiciales, incluso en una situación puramente interna, se basen en normas mínimas comunes. La conclusión es, pues, que las normas de ambas Directivas han de ser aplicadas por las autoridades competentes de los Estados miembros en todo proceso penal aunque en los hechos enjuiciados no exista ninguna dimensión transfronteriza ${ }^{67}$.

${ }^{66}$ Claramente partidaria de superar el enfoque funcional que el art. 82.2 TFUE imprime a la aproximación de legislaciones, sustituyéndolo por uno que la independice de la cooperación judicial y fomente una cultura de los derechos fundamentales en la UE, se muestra Ouwerkerk (2019, pp. 89-96). Argumenta su posición, subrayando de un lado que en la actualidad el fin más relevante de las Directivas sobre derechos y garantías procesales es dotar de contenido a los derechos procesales reconocidos en la CDFUE y, de otro, que uno de los efectos de la transposición en los ordenamientos nacionales de aquellas Directivas es el aumento de causas penales que tienen una conexión con el derecho UE.

El cambio de perspectiva desde la que son analizadas las normas mínimas contenidas en aquellas Directivas, pasando de estar circunscritas a su función de facilitar la cooperación judicial a destacar su contribución al refuerzo de la protección de los derechos y garantías procesales en la UE, es examinada también por Mitsilegas (2019, pp. 585-590).

67 Son las sentencias del TJUE dictadas en los asuntos Moro (2019) y VW (2020). En ambas, el Tribunal de Luxemburgo asume la conclusión del Abogado General, 
En definitiva, el diseño en exceso genérico del ámbito de aplicación material de las Directivas referentes a los derechos y garantías procesales, sobre el que además ha ahondado la jurisprudencia del TJUE dotándolo de una considerable fuerza expansiva, convierte en un ejercicio difícil establecer una clara delimitación de las esferas que corresponden a la UE y a los Estados miembros en el desarrollo de la competencia que comparten en lo atinente al espacio de libertad, seguridad y justicia ${ }^{68}$.

El segundo criterio se funda en la íntima conexión que ha de haber entre la cláusula de "no regresión" y la implementación de las normas de la Directiva por el legislador nacional. De ahí que cuando no exista tal vínculo aquella cláusula no debería ser aplicada. En otros términos, cuando la "reducción" en los estándares nacionales de protección de un derecho o garantía procesal no se halle ligada a la transposición de la Directiva sino que constituya una medida que forme parte de una política legislativa adoptada para hacer frente a una situación puramente nacional, la cláusula de "no regresión" no ha de ser un obstáculo para que emprender la correspondiente reforma legal.

Y, finalmente, el tercer criterio atañe al objeto de la prohibición de las cláusulas de "no regresión". Estas cláusulas ordenan las relaciones entre el Derecho de la UE y los Derechos nacionales. De ahí que no pueden equipararse a las cláusulas standstill, o de consolidación, de carácter exclusivamente nacional y que fijan las legislaciones de los Estados miembros a la fecha de la entrada en vigor del instrumento normativo UE. Las cláusulas de "no regresión" no pueden prohibir, con carácter absoluto, la modificación de una ley nacional que pueda disminuir el nivel de protección que concedía a un derecho procesal. Si así fuera se obstaculizaría la acción de los Estados miembros en materias respecto de las que mantienen su competencia. Lo que sí prohíben las cláusulas de "no regresión" es que el Estado miembro, amparándose exclusivamente en el contenido de las normas mínimas de la Directiva, proceda a reducir la protección ya garantizada a un derecho procesal por su propio ordenamiento. En definitiva, mediante las cláusulas de "no regre-

según la cual, no solo las dos Directivas cuyas normas son interpretadas en las sentencias referidas sino todas las Directivas que establecen reglas mínimas en los procesos penales, no requieren para ser aplicables que el caso concreto sometido al tribunal nacional presente una dimensión transfronteriza. Afirma que tal dimensión solo se predica de la cooperación judicial pero no ha de afectar a la armonización, pues el objetivo de esta última radica en crear un entorno común en el que se garanticen normas mínimas de carácter general y previo, por tanto, sin estar condicionadas por la posible existencia de un elemento transfronterizo específico y posterior (cfr. ap. 30-53 de las conclusiones al asunto Moro, 2019).

$68 \mathrm{Vid}$. sobre este tema el acertado análisis efectuado por De Hoyos Sancho (2019a, pp. 54-57). Ahora bien, la misma autora, en otro trabajo reciente (2019b, pp. 36-47) demuestra a través del análisis de sentencias del TJUE la diferente intensidad que despliegan los principios de subsidiariedad y autonomía procesal en función de si, en los asuntos que dan lugar a las cuestiones prejudiciales, existe o no un componente transnacional y, en consecuencia, está en juego o no la eficacia de la cooperación judicial. 
sión” se impide que la transposición de la Directiva pueda constituir por sí sola un motivo válido para llevar a cabo aquella reducción.

No obstante, incluso atribuyendo a la cláusula de "no regresión" de la Dir. 2016/800 la eficacia propia de una cláusula standstill, debería precisarse que no concurren en la práctica forense nacional de hoy en día los dos presupuestos básicos que la definen. Así, en primer lugar, no existe ese nivel de protección establecido previamente ya que, como se ha expuesto, en la actualidad se están enjuiciando en ausencia a menores acusados. Y, en segundo lugar, aun estimando que se reduce el nivel de protección del derecho a estar presente en el propio juicio, la disminución no operaría con carácter general, sino que solo recaería sobre una parte de los menores acusados.

En definitiva, en el enjuiciamiento en ausencia de menores se trataría de respetar un cierto margen de apreciación nacional, que el TJUE ya ha aplicado en materia de derechos fundamentales, que permitiría aceptar la legitimidad del objetivo que el legislador español pretende lograr con la reforma de la LO 5/2000 y le atribuiría la facultad de determinar la necesidad y proporcionalidad de la medida que adoptara ${ }^{69}$.

\section{CONCLUSIONES}

De acuerdo con la jurisprudencia del TEDH un juicio justo requiere, como regla, que se celebre estando presente la persona acusada. No obstante, esa misma jurisprudencia ha señalado que el derecho a estar presente en el propio juicio no es absoluto, sino que concurriendo determinadas circunstancias el hecho de juzgar en ausencia no debe entenderse que vulnera el derecho a un proceso equitativo consagrado en el art. 6.1 CEDH.

Como se ha podido comprobar, la jurisprudencia del TEDH ha servido de base a la regulación de las condiciones previstas, de un lado, en las Decisiones marco 2002/584/JAI y 2009/299/JAI y, de otro, en la Dir. 2016/343, para que las personas acusadas, incluyendo a las menores de edad responsables penalmente, puedan ser juzgadas en ausencia. Por el contrario, ninguna regulación específica ha adoptado la Dir. 2016/800 que efectúa una remisión en lo atinente al derecho de los menores a estar presentes en el propio juicio a la Dir. 2016/343. En consecuencia, los estándares fijados en esta última Directiva se erigen en las normas mínimas que deben ser respetadas por todos los Estados miembros cuando procedan a incorporar, a sus respectivos ordenamientos, el enjuiciamiento en ausencia de menores acusados.

Ante la inseguridad jurídica provocada por la dispar interpretación y aplicación a cargo de los tribunales españoles de la normativa interna en lo que

69 Sobre la utilización de la doctrina del margen de apreciación nacional por el TJUE cuando supervisa la actividad de las autoridades nacionales que afectan a derechos fundamentales, vid. Díaz Crego (2009, pp. 57-72). 
respecta a la validez del enjuiciamiento de menores acusados en ausencia, es razonable estimar que es imprescindible que se proceda a regular de forma clara y precisa su admisibilidad.

Un examen desde la óptica de valores y principios que informan el CEDH, el derecho de la UE y el ordenamiento jurídico español pone de manifiesto que si en un sentido amplio la celebración del juicio en ausencia del acusado se justifica, siempre que se salvaguarde el derecho a un juicio equitativo, en la realización del interés público, especificando que se evita la pérdida de fuentes de prueba, la comisión de errores judiciales y la denegación de justicia para las víctimas, cuando se trata de menores acusados se añade el principio del superior interés del menor que puede reforzar los argumentos favorables a la celebración del juicio en ausencia.

A lo anterior debe sumarse que un análisis de la práctica forense y la consideración de la Administración de Justicia como servicio público reclaman que haya de valorarse lo que la jurisprudencia nacional está poniendo de relieve. Y ello porque incluso aquellos tribunales que sostienen que el art. 35 LO 5/2000 es una norma completa, que impone la inexcusable presencia del menor en la fase de audiencia, no siendo correcto aplicar de forma supletoria los preceptos que disciplinan la tramitación del procedimiento abreviado, matizan que cabe una excepción a aquella regla general de modo que ha de ser posible el juicio en ausencia cuando la acusación se fundamenta en la perpetración de un delito menos grave o leve. Si no se permitiera el enjuiciamiento en estos casos, la suspensión de la audiencia dependería de la mera voluntad de los menores ya que no sería legal acordar su detención, pues, implicaría una restricción de derechos de mayor intensidad a la generada por la medida sancionadora pedida por las acusaciones.

Un aspecto complejo con el que deberá enfrentarse la futura iniciativa legislativa va a ser la repercusión que ha de tener la cláusula de "no regresión" establecida en la Dir. 2016/800. A nuestro entender, tal cláusula opera respecto de las condiciones, de acuerdo con las cuales pueden los menores ser juzgados en ausencia, en las regulaciones nacionales que ya preveían tal posibilidad antes de la entrada en vigor de la citada Directiva. En cambio, la cláusula de "no regresión", a causa de su naturaleza y finalidad, no puede ser considerada un óbice para la regulación del enjuiciamiento en ausencia de menores acusados en aquellos Estados miembros que, como España, no disponen de normas de derecho positivo específicas sobre el tema, a lo que debe añadirse que una actuación legislativa en el sentido indicado viene requerida por las graves consecuencias derivadas de las divergencias judiciales ya expuestas que son un problema meramente interno y, por tanto, sin relación directa con la transposición de aquella Directiva. 


\section{FUENTES CITADAS}

\section{A. Bibliografía}

Ambos, K. (2017). Derecho penal europeo. Civitas-Thomson Reuters.

Arangüena Fanego, C. (2019). Las Directivas europeas de armonización de garantías procesales de investigados y acusados: Su implementación en el derecho español, Revista de Estudios Europeos, 1, 5-40. https://www.ree-uva.es/index.php/ sumarios/2019/n-extraordinario-monografico-1-2019.

Armenta Deu, T. (2019). Lecciones de Derecho procesal penal (12. ${ }^{\mathrm{a}}$ ed.). Marcial Pons.

Arold Lorenz, N. L.; Groussot, X., y Petursson, G. (2013). The European Human Rights Culture: a paradox of human rights protection in Europe? Martinus Nijhoff Publishers.

Bachmaier Winter, L. (2019). New developments in EU law in the field of in absentia national proceedings: the Directive 2016/343 in the light of the ECtHR case law. En S. Quattrocolo y S. Ruggeri (Eds.), Personal participation in criminal proceedings: a comparative study of participatory safeguards and in absentia trials in Europe (pp. 641-667). Springer.

Bellido Penadés, R. (2015). Generalización de la segunda instancia y apertura de la casación en el Proyecto de reforma de la Ley de Enjuiciamiento Criminal de 2015. Diario La Ley, n. ${ }^{\circ}$ 8618, Sec. Doctrina, 1-11. https://diariolaley.laleynext.es.

Bose, M. (2011). Harmonizing procedural rights indirectly: the framework on trials in absentia. North Carolina Journal of Internacional Law and Comercial Regulation, 37, 2, 489-510.

Brodersen, K. H.; Glerum, V., y Klip, A. (2020). The European arrest warrant and in absentia judgments. Eleven International Publishing.

Cedeño Hernán, M. (2010). La orden de detención y entrega europea: los motivos de denegación y condicionamiento de la entrega. Civitas-Thomson Reuters.

Conde-Pumpido Tourón, C., y Garberí Llobregat, J. (2003). Los juicios rápidos, el procedimiento abreviado y el juicio de faltas, I. Bosch.

Cortés Domínguez, V. (2019). Recursos de apelación contra las resoluciones definitivas. En V. Moreno Catena y V. Cortés Domínguez, Derecho Procesal Penal (9. ${ }^{a}$ ed., pp. 621-635). Tirant lo Blanch.

Cras, S. (2016). The Directive on procedural safeguards for children who are suspects or acused persons in criminal proceedings. Eucrim, 2, 109-120. https://eucrim.eu/ issues/2016-02/.

Cras, S., y Erbežnik, A. (2016). The Directive on the presumption of innocence and the right to be present at trial. Eucrim, 1, 25-36. https://eucrim.eu/issues/2016-01/.

De Hoyos Sancho, M. (2019a). El juez español y la compleja cuestión de la determinación del ámbito de aplicación del derecho de la Unión Europea: en particular, en materia de garantías procesales de investigados y acusados. Revista de Estudios Europeos, 1, 41-65. https:// uva.es/index.php/sumarios/2019/n-extraordinario-monografico-1-2019.

- (2019b). El principio de subsidiariedad y la autonomía procesal de los Estados de la Unión Europea: interpretación jurisprudencial en materia procesal penal. Jueces para la democracia, 96, 36-47.

Díaz Crego, M. (2009). El margen de apreciación nacional en la jurisprudencia del Tribunal de Justicia de las Comunidades Europeas referida a los derechos fundamentales. En J. García Roca y P. A. Fernández Sánchez (Coords.), Integración europea a través de derechos fundamentales: de un sistema binario a otro integrado (pp. 55-77). Centro de Estudios Políticos y Constitucionales. 
Etxeberría Guridi, J. F. (2019). Los recursos (I). En J. Montero Aroca, J. L. Gómez Colomer, S. Barona Vilar, I. Esparza Leibar y J. F. Etxeberría Guridi, Derecho Juris-

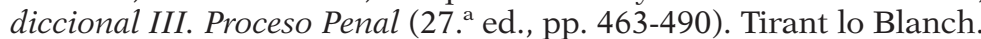

Fernández López, M. (2005). Prueba y presunción de inocencia. Iustel.

Fernández-Gallardo Fernández-Gallardo, J. A. (2015). Perspectiva actual del juicio en ausencia del acusado. Cuadernos de Política Criminal, 117, 219-269.

Garberí Llobregat, J. (1992). La ausencia del acusado del proceso penal: especial referencia al proceso penal abreviado (L.O. 7/1988, de 28 de diciembre). Colex.

García Roca, J. (2009). Soberanía estatal versus integración europea mediante unos derechos fundamentales comunes: ¿cuál es el margen de apreciación nacional? En J. García Roca y P. A. Fernández Sánchez (Coords.), Integración europea a través de derechos fundamentales: de un sistema binario a otro integrado (pp. 15-53). Centro de Estudios Políticos y Constitucionales.

Gimeno Sendra, V. (1989). La defensa. En V. Moreno Catena, J. Almagro Nosete, V. Cortés Domínguez y V. Gimeno Sendra, El nuevo proceso penal: estudios sobre la Ley Orgánica 7/1998 (pp. 113-126). Tirant lo Blanch.

González Pillado, E. (2019). Implicaciones de la Directiva (UE) 2016/800, relativa a las garantías procesales de los menores sospechosos o acusados en los procesos penales, en la Ley de responsabilidad penal del menor. Revista General de Derecho Europeo, 48, 59-97. https:/www.iustel.com//v2/revistas/detalle_revista. asp?id=13\&numero $=48$.

González-Cuéllar Serrano, N. (2015). La reforma de los recursos de apelación, casación y revisión. En M. Marchena Gómez y N. González-Cuéllar Serrano. La reforma de la Ley de enjuiciamiento criminal en 2015 (pp. 533-538). Ediciones Jurídicas Castillo de Luna.

Guerrero Palomares, S. (2018). Algunas cuestiones y propuestas sobre la construcción teórica del derecho a la presunción de inocencia, a la luz de la Directiva 2016/343, de 9 de marzo, del Parlamento Europeo y del Consejo, por la que se refuerzan en el proceso penal determinados aspectos de la presunción de inocencia y el derecho a estar presente en el juicio. En C. Arangüena Fanego y M. de Hoyos Sancho (Dirs.), y B. Vidal Fernández (Coord.), Garantías procesales de investigados y acusados: situación actual en el ámbito de la Unión Europea (pp. 143-175). Tirant lo Blanch.

Gutiérrez Berlinches, A. (2008). La celebración del juicio oral en ausencia del acusado: sus ventajas e inconvenientes. Revista de Derecho Procesal, 203-256.

- (2009). Reconocimiento de resoluciones penales dictadas en ausencia del acusado: las limitaciones derivadas de la jurisprudencia constitucional a la luz de la legislación europea. Revista Española de Derecho Europeo, 30, 159-172. http://www.revistasmarcialpons.es/revistaespanoladerechoeuropeo/issue.

Jimeno Bulnes, M. (2011a). Un proceso europeo para el siglo XXI. Civitas-Thomson Reuters.

- (2011b). Régimen y experiencia práctica de la orden de detención europea. En M. Jimeno Bulnes (Coord.), Justicia versus seguridad en el espacio judicial europeo: orden de detención europea y garantías procesales (pp. 109-200). Tirant lo Blanch.

Mangas Martín, A. (2005). La constitución europea. Iustel.

- (2014). Las competencias de la Unión Europea. En A. Mangas Martín y D. J. Liñán Nogueras, Instituciones y Derecho de la Unión Europea (8. ${ }^{a}$ ed., pp. 69-86). Tecnos.

Martin y Pérez de Nanclares, J. (2008). Artículo 53. Nivel de protección. En A. Mangas Martín (Dir.), Carta de los Derechos Fundamentales de la Unión Europea. Comentario artículo por artículo (1. ${ }^{\mathrm{a}}$ ed., pp. 852-869). Fundación BBVA.

Mitsilegas, V. (2019). The European model of judicial cooperation in criminal matters: towards effectiveness based on earned trust. Revista Brasileira de Directo Processual Penal, 5, 2, pp. 565-594. 
Monereo Pérez, J. L. (2012). Artículo 53. Nivel de protección. En C. Monereo Atienza y J. L. Monereo Pérez (Dir. y Coord.), La Europa de los derechos: estudio sistemático de la Carta de los Derechos Fundamentales de la Unión Europea (pp. 1397-1415). Comares.

Morenilla Allard, P. (2007). El proceso penal del menor: actualizado a la LO 8/2006 de 4 de diciembre. Colex.

Muerza Esparza, J. (2015). Las reformas procesales penales de 2015: nuevas medidas de agilización, de investigación y de fortalecimiento de garantías en la justicia penal. Aranzadi-Thomson Reuters.

Ouwerkerk, J. (2019). EU competence in the area of procedural criminal law: functional vs. self-standing approximation of procedural rights and their progressive effect on the Charter's scope of application. European Journal of Crime, Criminal Law and Criminal Justice, 27, 89-96.

Peers, S. (2010). Non-regression clauses: the fig leaf has fallen. Industrial Law Journal, 39, 436-443.

Pérez Machío, A. I. (2007), El tratamiento jurídico-penal de los menores infractores - LO 8/2006-: aspectos de derecho comparado y especial consideración del menor infractor inmigrante. Tirant lo Blanch.

Ruggeri, S. (2016). Inaudito reo proceedings, defence rights, and harmonization goals in the EU. Eucrim, 1, 42-51. https://eucrim.eu/issues/2016-01/.

- (2019). Personal participation in criminal proceedings, in absentia trials and inaudito reo procedures: solution models and deficiencies in ECtHR case-law. En S. Quattrocolo y S. Ruggeri (Eds.), Personal participation in criminal proceeding: a comparative study of participatory safeguards and in absentia trials in Europe (pp. 579-604). Springer.

Schneider, A. (2019). In absentia trials and transborder criminal procedures: the perspective of EU law. En S. Quattrocolo y S. Ruggeri (Eds.), Personal participation in criminal proceedings: a comparative study of participatory safeguards and in absentia trials in Europe (pp. 605-639). Springer.

Serrano Masip, M. (2016). Garantías procesales penales específicas reconocidas a menores sospechosos o acusados. En M. Jimeno Bulnes (Dir.), Aproximación legislativa versus reconocimiento mutuo en el desarrollo del espacio judicial europeo: una perspectiva multidisciplinar (pp. 211-263). Bosch.

Tomé García, J. A. (2003). El procedimiento penal del menor tras la ley 38/2002, de reforma parcial de la Ley de Enjuiciamiento Criminal. Aranzadi.

Van de Heyning C. (2012). The natural 'home' of fundamental rights adjudication: constitutional challenges to the European Court of Human Rights. Yearbook of European Law, 31, 1, 128-161.

Van de Heyning, C. (2011). No place like home: discretionary space for the domestic protection of fundamental rights. En P. Popelier, C. Van de Hening y P. Van Nuffel, Human rights protection in the European legal order: the interaction between the European and national courts (pp. 65-96). Intersentia.

Vigneau, C. (2006). Les clauses de non-régression en droit communautaire du travail. Le Droit Ouvrier, novembre, 521-524.

Villamarín López, M. ${ }^{a}$ L. (2017). La Directiva europea 2016/343, de 9 de marzo, sobre presunción de inocencia y el derecho a estar presente en el propio juicio. InDret, 3, 1-39. https://indret.com.

Vogel, B. (2019). Report on Germany. En S. Quattrocolo y S. Ruggeri (Eds.), Personal participation in criminal proceedings: a comparative study of participatory safeguards and in absentia trials in Europe (pp. 123-164). Springer. 


\section{B. Legislación y jurisprudencia}

Auto APM 231/2005 (24 de nov.). ECLI:ES:APM:2005:11629a.

Auto TC 148/1999 (14 de jun.). ECLI:ES:TC:1999:148a.

Carta de los Derechos Fundamentales de la Unión Europea. DOUE C 202 (7 de jun. de 2016).

Constitución Española. ES. BOE n. ${ }^{\circ} 311$ (29 de dic. de 1978).

Decisión marco 2002/584/JAI del Consejo, de 13 de junio de 2002, relativa a la orden de detención europea y a los procedimientos de entrega entre Estados miembros. DOUE L 190 (18 de jul. de 2002).

Decisión Marco 2009/299/JAI del Consejo, de 26 de febrero de 2009, por la que se modifican las Decisiones Marco 2002/584/JAI, 2005/214/JAI, 2006/783/JAI, 2008/909/ JAI y 2008/947/JAI, destinada a reforzar los derechos procesales de las personas y a propiciar la aplicación del principio de reconocimiento mutuo de las resoluciones dictadas a raíz de juicios celebrados sin comparecencia del imputado. DOUE L 81 (27 de mar. de 2009).

Decisión TEDH. (2006). Battisti c. Francia, ECLI:CE:ECHR:2006:1212DEC002879605

Directiva (UE) 2016/343 del Parlamento Europeo y del Consejo, de 9 de marzo de 2016, por la que se refuerzan en el proceso penal determinados aspectos de la presunción de inocencia y el derecho a estar presente en el juicio. DOUE L 65 (11 de mar. de 2016).

Directiva (UE) 2016/800 del Parlamento Europeo y del Consejo, de 11 de mayo de 2016, relativa a las garantías procesales de los menores sospechosos o acusados en los procesos penales. DOUE L 132 (21 de mayo de 2016).

Directiva 1999/70/CE del Consejo, de 28 de junio de 1999, relativa al Acuerdo marco de la CES, la UNICE y el CEEP sobre el trabajo de duración determinada. DOCE L 175 (10 de jul. de 1999).

Directiva 2000/78/CE del Consejo, de 27 de noviembre de 2000, relativa al establecimiento de un marco general para la igualdad de trato en el empleo y la ocupación. DOCE L 303 (2 de dic. de 2000).

Directiva 2012/13/UE del Parlamento Europeo y del Consejo, de 22 de mayo de 2012, relativa al derecho a la información en los procesos penales. DOUE L 142 (1 de jun. de 2012).

Directiva 2013/48/UE del Parlamento Europeo y del Consejo, de 22 de octubre de 2013, sobre el derecho a la asistencia de letrado en los procesos penales y en los procedimientos relativos a la orden de detención europea, y sobre el derecho a que se informe a un tercero en el momento de la privación de la libertad y a comunicarse con terceros y con autoridades consulares durante la privación de libertad. DOUE L 294 (6 de nov. de 2013).

Instrumento de Ratificación del Convenio para la Protección de los Derechos Humanos y de las Libertades Fundamentales, hecho en Roma el 4 de noviembre de 1950, y enmendado por los Protocolos adicionales números 3 y 5, de 6 de mayo de 1963 y 20 de enero de 1966, respectivamente. ES. BOE n. ${ }^{\circ} 243$ (10 de oct. de 1979).

Ley $23 / 2014$, de 20 de noviembre, de reconocimiento mutuo de resoluciones penales en la Unión Europea. ES. BOE n. ${ }^{\circ} 282$ (21 de nov. de 2014).

Ley 3/1967, de 8 de abril, sobre modificación de determinados artículos del Código Penal y de Ley de Enjuiciamiento Criminal. ES. BOE n. ${ }^{\circ} 86$ (11 de abr. de 1967).

Ley 3/2018, de 11 de junio, por la que se modifica la Ley 23/2014, de 20 de noviembre, de reconocimiento mutuo de resoluciones penales en la Unión Europea, para regular la Orden Europea de Investigación. ES. BOE n. ${ }^{\circ} 142$ (12 de jun. de 2018).

Ley 38/2002, de 24 de octubre, de reforma parcial de la Ley de Enjuiciamiento Criminal, sobre el procedimiento para el enjuiciamiento rápido e inmediato de deter- 
minados delitos y faltas, y de modificación del procedimiento abreviado. ES. BOE n. ${ }^{\circ} 258$ ( 28 de oct. de 2002$)$.

Ley 41/2015, de 5 de octubre, de modificación de la Ley de Enjuiciamiento Criminal para la agilización de la justicia penal y el fortalecimiento de las garantías procesales. ES. BOE n. ${ }^{\circ} 239$ (6 de oct. de 2015).

Ley Orgánica 1/2015, de 30 de marzo, por la que se modifica la Ley Orgánica 10/1995, de 23 de noviembre, del Código Penal. ES. BOE n. ${ }^{\circ} 77$ (31 de mar. de 2015).

Ley Orgánica 10/1980, de 11 de noviembre, de enjuiciamiento oral de delitos dolosos, menos graves y flagrantes. ES. BOE n. 280 (21 de nov. de 1980).

Ley Orgánica 13/2015, de 5 de octubre, de modificación de la Ley de Enjuiciamiento Criminal para el fortalecimiento de las garantías procesales y la regulación de las medidas de investigación tecnológica. ES. BOE n. ${ }^{\circ} 239$ (6 de oct. de 2015).

Ley Orgánica 5/2000, de 12 de enero, reguladora de la responsabilidad penal de los menores. ES. BOE n. ${ }^{\circ} 11$ (30 de ene. de 2000).

Ley Orgánica 7/1988, de 28 de diciembre, de los Juzgados de lo Penal, y por la que se modifican diversos preceptos de las Leyes Orgánica del Poder Judicial y de Enjuiciamiento Criminal. ES. BOE n. ${ }^{\circ} 313$ (30 de dic. de 1988).

Ley Orgánica 8/2012, de 27 de diciembre, de medidas de eficiencia presupuestaria en la Administración de Justicia, por la que se modifica la Ley Orgánica 6/1985, de 1 de julio, del Poder Judicial. ES. BOE n. 312 (28 de dic. de 2012).

Real Decreto de 14 de septiembre de 1882. Ley Enjuiciamiento Criminal. ES. Gaceta n. ${ }^{\circ} 260$ (17 de sep. de 1882).

Sentencia APA 278/2013 (13 de mayo). ECLI:ES:APA:2013:4084.

Sentencia APB 40/2010 (4 de ene.). ECLI:ES:APB:2010:55.

Sentencia APBI 28/2018 (16 de abr.). ECLI:ES:APBI:2018:660.

Sentencia APBI 47/2005 (8 de sep.). ECLI:ES:APBI:2005:2162.

Sentencia APC 45/2016 (28 de ene.). ECLI:ES:APC:2016:63.

Sentencia APCO 198/2018 (15 de mayo). ECLI:ES:APCO:2018: 373.

Sentencia APCU 50/2005 (25 de mayo). ECLI:ES:APCU:2004:222.

Sentencia APL 133/2013 (24 de abr.). ECLI:ES:APL:2013:290.

Sentencia APLE 77/2006 (1 de jun.). ECLI:ES:APLE:2006:663.

Sentencia APM 124/2020 (6 de abr.). ECLI:ES:APM:2020:3123.

Sentencia APM 229/2004 (21 de dic.). ECLI:ES:APM:2004:16275.

Sentencia APM 52/2014 (18 de feb.). ECLI:ES:APM:2014:4219.

Sentencia APM 56/2019 (21 de feb.). ECLI:ES:APM:2019:13811.

Sentencia APO 82/2020 (4 de mar.). ECLI:ES:APO:2020:1547.

Sentencia APOU 367/2012 (9 de oct.). ECLI:ES:APOU:2012:727.

Sentencia APPO 226/2015 (11 de mayo). ECLI:ES:APPO:2015:959.

Sentencia APSS 254/2014 (17 de oct.). ECLI:ES:APSS:2014:765.

Sentencia APV 377/2018 (11 de jul.). ECLI:ES:APV:2018:2677.

Sentencia TC 120/2009 (18 de may.). ECLI:ES:TC:2009:120.

Sentencia TC 24/2018 (5 de mar.) ECLI:ES:TC:2018:24.

Sentencia TC 87/1984 (27 de jul.). ECLI:ES:TC:1984:87.

Sentencia TC 91/2000 (30 de mar.). ECLI:ES:TC:2000:91.

Sentencia TEDH. (1970). Delcourt c. Bélgica, 2689/65. ECLI:CE:ECHR:1970:0117J UD000268965.

Sentencia TEDH. (1976). Handyside c. Reino Unido, 5493/72. ECLI:CE:ECHR:1976:1 207JUD000549372.

Sentencia TEDH. (1985). Colozza c. Italia, 9024/80. ECLI:CE:ECHR:1985:0212J UD000902480.

Sentencia TEDH. (1988). Ekbatani c. Suecia, 10563/83. ECLI:CE:ECHR: 1988:0526 JUD001056383. 
Sentencia TEDH. (1990). Håkansson y Sturesson c. Suecia, 11855/85. ECLI:CE:ECHR :1990:0221JUD001185585.

Sentencia TEDH. (1991). Fejde c. Suecia, 12631/87. ECLI:CE:ECHR:1991:1029J UD001263187.

Sentencia TEDH. (1992). Open Door y Dublin Well Woman c. Irlanda, 14234/88 14235/88. ECLI:CE:ECHR:1992:1029JUD001423488

Sentencia TEDH. (1992). Pfeifer y Plankl c. Austria, 10802/84. ECLI:CE:ECHR:1992:0 225JUD001080284.

Sentencia TEDH. (1993). Poitrimol c. Francia, 14032/88. ECLI:CE:ECHR:1993:1123J UD001403288.

Sentencia TEDH. (1994). Burghartz c. Suiza, 16213/90. ECLI:CE:ECHR:1994:0222J UD001621390.

Sentencia TEDH. (1994). Lala c. Holanda, 14861/89. ECLI:CE:ECHR:1994:0922J UD001486189.

Sentencia TEDH. (1994). Pelladoah c. Holanda, 16737/90. ECLI:CE:ECHR:1994:0922 JUD001673790.

Sentencia TEDH. (1996). Botten c. Noruega, 16206/90. ECLI:CE:ECHR:1996:0219J UD001620690.

Sentencia TEDH. (1999). Van Geyseghem c. Bélgica, 26103/95. ECLI:CE:ECHR:1999: 0121JUD002610395.

Sentencia TEDH. (2000). Constantinescu c. Rumanía, 28871/95. ECLI:CE:ECHR:200 0:0627JUD002887195.

Sentencia TEDH. (2001). Krombach c. Francia, 29731/96. ECLI:CE:ECHR:2001:0213 JUD002973196.

Sentencia TEDH. (2001). Medenica c. Suiza, 20491/92. ECLI:CE:ECHR:2001:0614J UD002049192.

Sentencia TEDH. (2003). Jones c. Reino Unido, 30900/02. ECLI:CE:ECHR:2003:0909 DEC003090002.

Sentencia TEDH. (2004). Somogyi c. Italia, 67972/01. ECLI:CE:ECHR:2004:0518J UD006797201.

Sentencia TEDH. (2006). Hermi c. Italia, 18114/02. ECLI:CE:ECHR:2006:1018J UD001811402.

Sentencia TEDH. (2006). Sejdovic c. Italia, 56581/00. ECLI:CE:ECHR:2006:0301J UD005658100.

Sentencia TEDH. (2008). Bazo González c. España, 30643/04. ECLI:CE:ECHR:2008:1 216JUD003064304.

Sentencia TEDH. (2008). Demeboukov c. Bulgaria, 68020/01. ECLI:CE:ECHR:2008:0 228JUD006802001.

Sentencia TEDH. (2008). Spînu c. Rumanía, 32030/02. ECLI:CE:ECHR:2008:0429J UD003203002.

Sentencia TEDH. (2009). Aliykov c. Bulgaria, 333/04. ECLI:CE:ECHR:2009:1203J UD000033304.

Sentencia TEDH. (2009). Seliwiak c. Polonia, 3818/04. ECLI:CE:ECHR:2009:0721J UD000381804.

Sentencia TEDH. (2011). Faniel c. Bélgica, 11892/08. ECLI:CE:ECHR:2011:0301J UD001189208.

Sentencia TEDH. (2011). Valbuena Redondo c. España, 21460/08. ECLI:CE:ECHR:20 11:1213JUD002146008.

Sentencia TEDH. (2012). Haralampiev c. Bulgaria, 29648/03. ECLI:CE:ECHR:2012:0 424JUD002964803.

Sentencia TEDH. (2012). Neziraj c. Alemania, 30804/07. ECLI:CE:ECHR:2012:1108J UD003080407. 
Sentencia TEDH. (2015). Mihelj c. Eslovenia, 14204/07. ECLI:CE:ECHR:2015:0115J UD001420407.

Sentencia TEDH. (2015). Sanader c. Croacia, 66408/12. ECLI:CE:ECHR:2015:0212J UD006640812.

Sentencia TEDH. (2015). Tolmachev c. Estonia, 73748/13. ECLI:CE:ECHR: 2015:0709JUD007374813.

Sentencia TEDH. (2016). Arps c. Croacia, 23444/12. ECLI:CE:ECHR:2016:1025J UD002344412.

Sentencia TEDH. (2016). Hernández Royo c. España, 16033/12. ECLI:CE:ECHR:2016 :0920JUD001603312.

Sentencia TEDH. (2017). Frolovs c. Letonia, 13289/06. ECLI:CE:ECHR:2017:0615J UD001328906.

Sentencia TEDH. (2017). Hokkeling c. Holanda, 30749/12. ECLI:CE:ECHR:2017:021 4JUD003074912.

Sentencia TEDH. (2017). Lena Atanasova c. Bulgaria, 52009/07. ECLI:CE:ECHR:2017 :0126JUD005200907.

Sentencia TEDH. (2018). Dridi c. Alemania, 35778/11. ECLI:CE:ECHR:2018:0726J UD003577811.

Sentencia TEDH. (2018). Karemani c. Albania, 48717/08. ECLI:CE:ECHR:2018:0925 JUD004871708.

Sentencia TEDH. (2018). M.T.B. c. Turquía, 47081/06. ECLI:CE:ECHR:2018:0612J UD004708106.

Sentencia TEDH. (2018). Pirozzi c. Bélgica, 21055/11. ECLI:CE:ECHR:2018:0417J UD002105511.

Sentencia TEDH. (2018). Vyacheslav Korchagin c. Rusia, 12307/16. ECLI:CE:ECHR:2 018:0828JUD001230716.

Sentencia TEDH. (2019). Styrmir Pór Bragason c. Islandia, 36292/2014. ECLI:CE:ECH R:2019:0716JUD003629214.

Sentencia TEDH. (2020). Pardo Campoy y Lozano Rodríguez c. España, 53421/15 y 53427/15. ECLI:CE:ECHR:2020:0114JUD005342115.

Sentencia TJUE. (2005). Mangold, C-144/04. ECLI:EU:C:2005:709

Sentencia TJUE. (2009). Angelidaki y otros, C-378/07 a C-380/07. ECLI:EU:C:2009:250.

Sentencia TJUE. (2010). Sorge, C-98/09. ECLI:EU:C:2010:369.

Sentencia TJUE. (2013). Melloni, C- 399/11. ECLI:EU:C:2013:107.

Sentencia TJUE. (2016). Dworzecki, C-108/16. ECLI:EU: C:2016:346.

Sentencia TJUE. (2017). Ardic, C-571/17. ECLI:EU:C:2017:1026.

Sentencia TJUE. (2017). Tupikas, C-270/17. ECLI:EU:C:2017:628.

Sentencia TJUE. (2017. Zdziaszek, C-271/17. ECLI:EU:C:2017:629.

Sentencia TJUE. (2019). Moro, C-646/17. ECLI:EUC:2019:489

Sentencia TJUE. (2020). TX y UW, C-688/18. ECLI:EU:C:2020:94.

Sentencia TJUE. (2020). VW, C-659/18. ECLI:EU:C:2020:201.

Sentencia TS 945/2013 (16 de dic.). ECLI:ES:TS:2013:6389.

Tratado de Funcionamiento de la Unión Europea (versión consolidada). DOUE C 202 (7 de jun. de 2016). 